النمو السكاتي والنمو الزراعي في ظل محدوديه الموارد المائيه

السطحيه لدول حوض دجله و القرات 190 -7 - .

*

ابي الوتار

مستخلص البحث

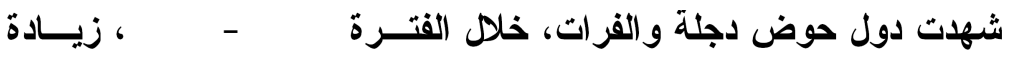

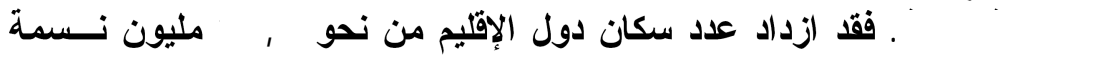

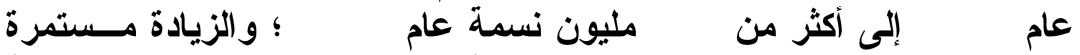

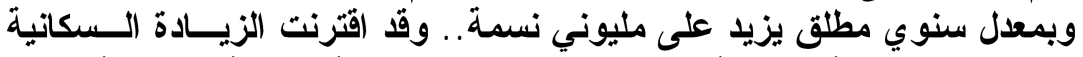

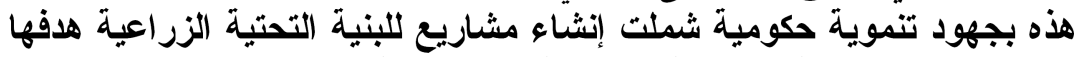

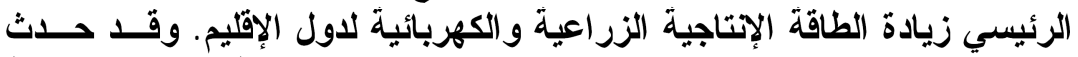

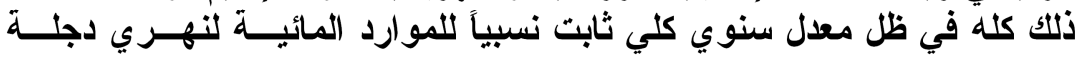

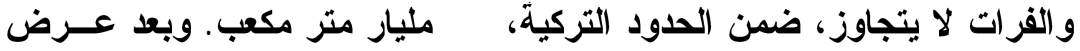

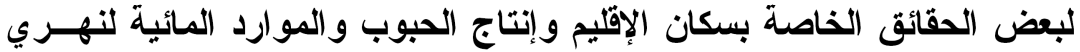

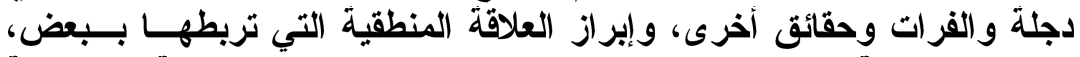

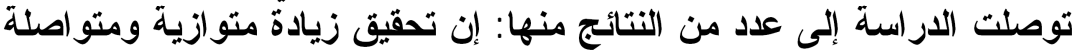

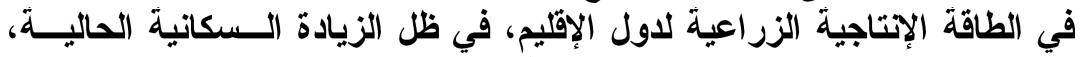
شيء غير ممكن.. وق تم الختاجة اعتام الار اسة بمقترحين.

كلمات مفتاحية: حوض دجلة والفرات، العلاقات الاقتصادية الاساسية، الزيادة الــسكانية، القــــى

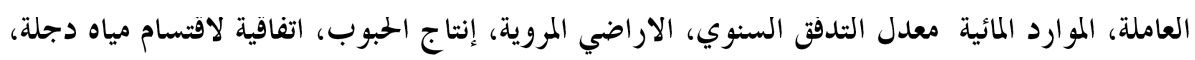
الطاقة الإنتاجية الزراعية.

مقدمه

إن بدت العلاقات الاقتصادية بين العراق ودول الجوار، وهي نزكيا

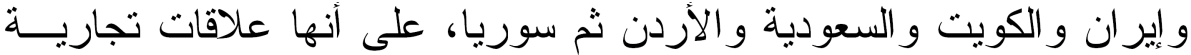

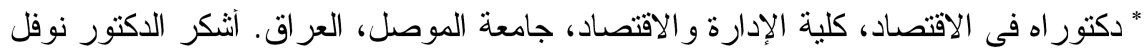

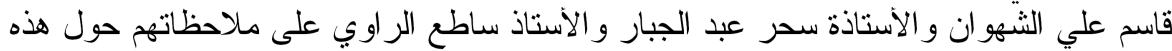
الورقة، دون إنشر اكهم في مسؤولية ما جاء فيها من أفكار أو أخطاء. 


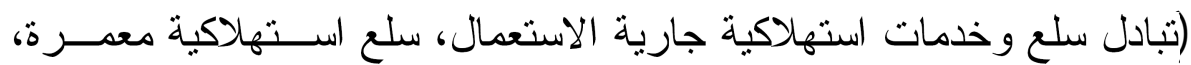

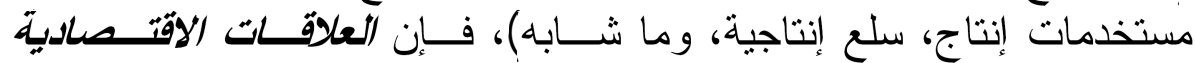

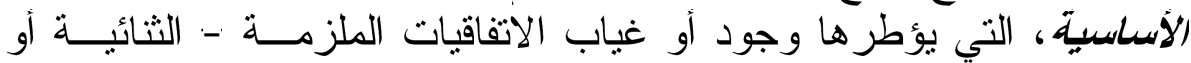

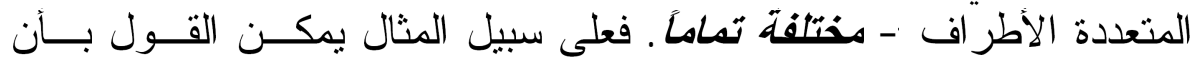

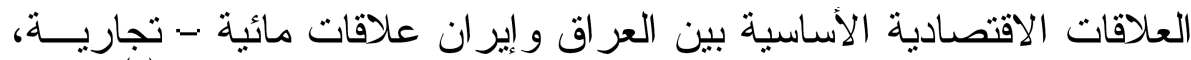

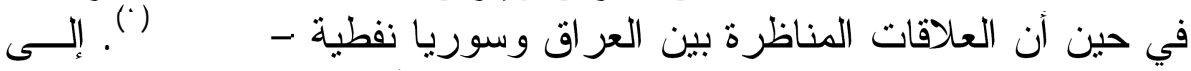

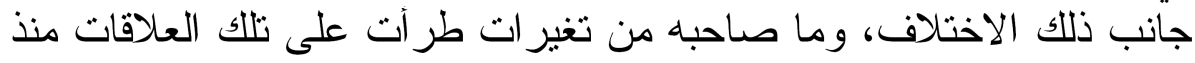

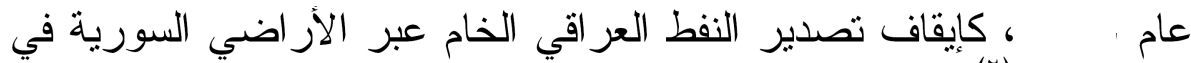

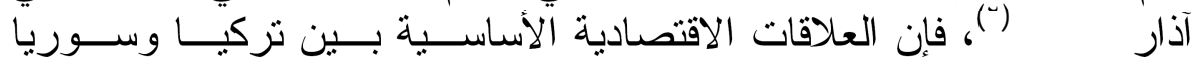

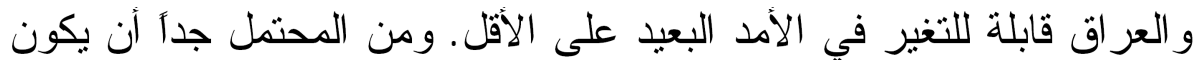

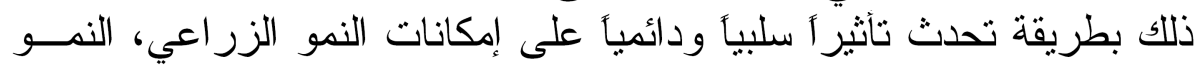

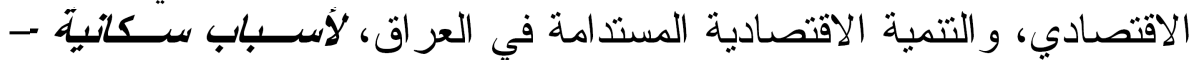

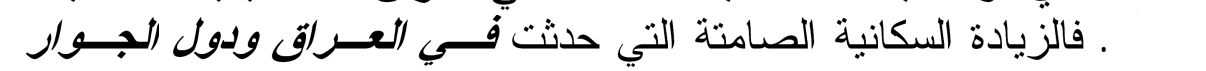

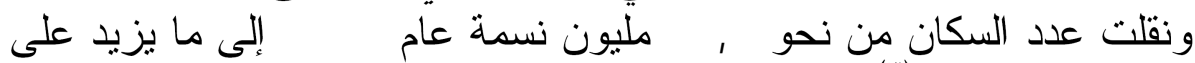

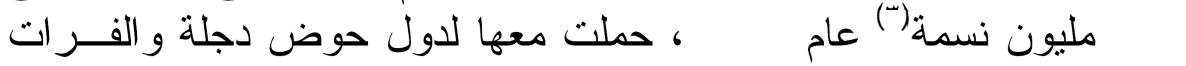

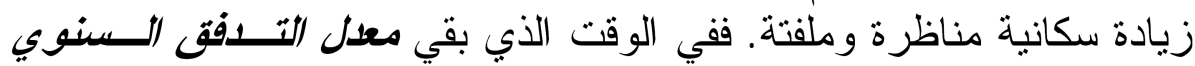

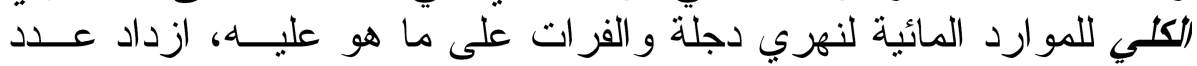

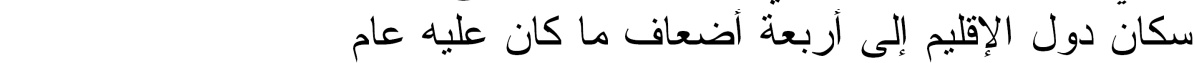

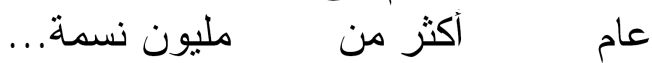

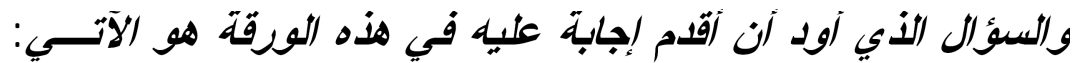

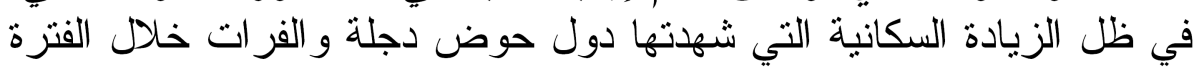

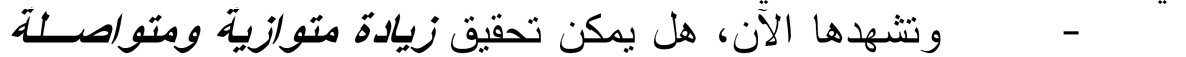

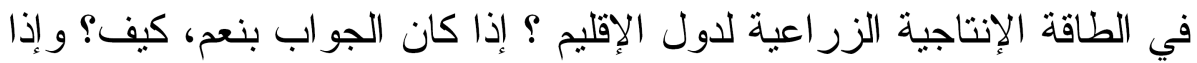

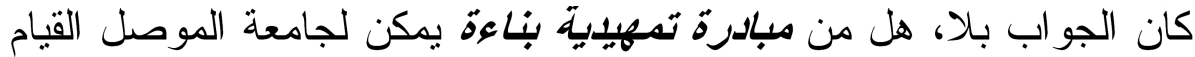
بها في هذا الخصوص اب بلان هن هن للإجابة على هذا السؤال قسمت الورقة إلى أربعة آقسام نم التركيز

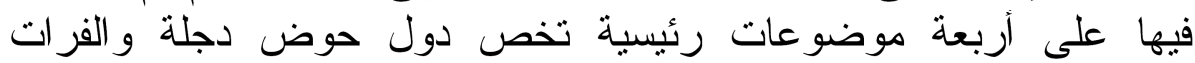

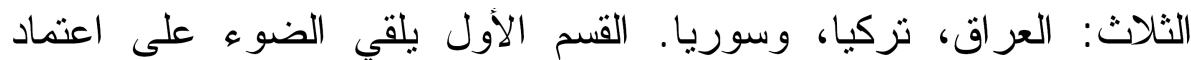

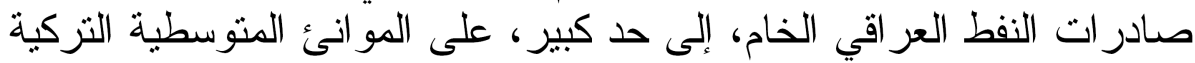

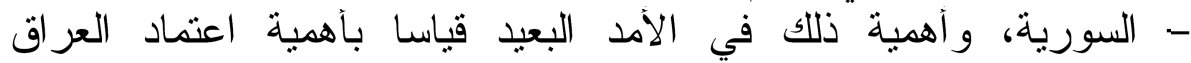
المائي الكبير على كل من تركيًا وسوريا في الأمد القصبير و الأمد البعيد معاً.

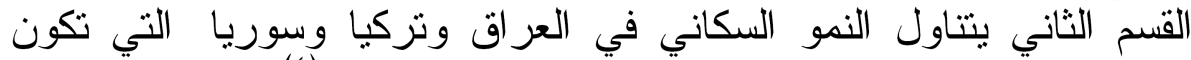

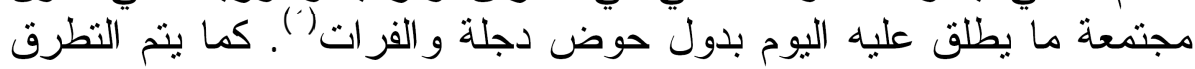
في هذا القسم إلى جانب من الجهود المهمة التي بذلت من آجل زيادة الطاقة 
$[\mathrm{rr}]$

أبي الونار

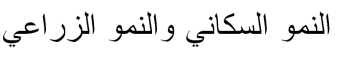

\begin{tabular}{|c|c|}
\hline \multicolumn{2}{|c|}{ o. r } \\
\hline & العدد \\
\hline 77,9 & $* \mid \wedge, \bigvee$ \\
\hline $7 V, \mu$ & દ१,५ \\
\hline , 7 & 9,7 \\
\hline & $\mathrm{VV}, 7$ \\
\hline
\end{tabular}

الإنتاجية الزراعية كجزء من الجهود التتموية العامة، استجابة للزيادة

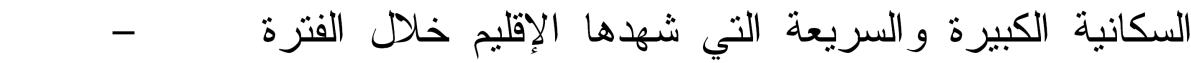

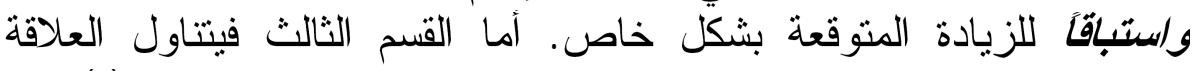

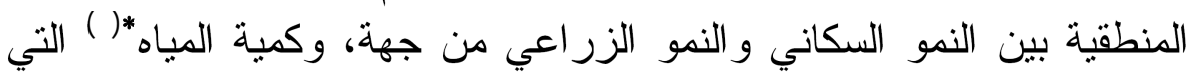

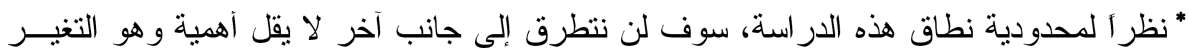

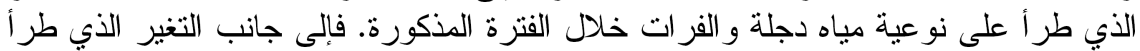

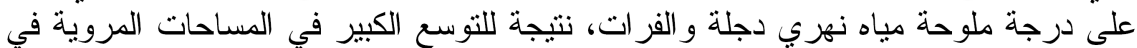

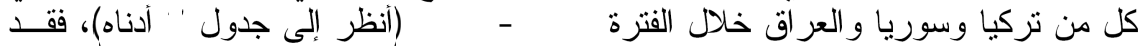

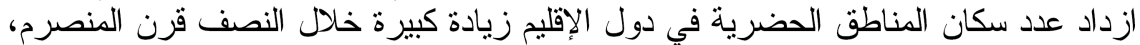

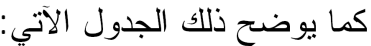

\begin{tabular}{|c|c|c|c|c|c|}
\hline \multicolumn{2}{|l|}{$r$} & \multicolumn{2}{|c|}{$19 v 0$} & \multicolumn{2}{|c|}{190.} \\
\hline \% & العدد & م النسبة & العدد & م النسبة & العدد \\
\hline $7 V, \Lambda$ & 17,9 & (7), & $7, \Lambda$ & $\mu 0,1$ & 1,9 \\
\hline $7 \varepsilon, \Lambda$ & $\varepsilon^{\mu}, r$ & દ1,0 & $|V|$, & $r \varepsilon, V$ & $0, \mu$ \\
\hline $0 \cdot, 1$ & $\Lambda, 1$ & $\varepsilon 0,1$ & $\mu, \varepsilon$ & $\mu \cdot, 7$ & 1,1 \\
\hline $0 \wedge, 7$ & $7 \Lambda, r$ & $\varepsilon 0, V$ & $r V, \mu$ & $r V, \varepsilon$ & $\mu$ \\
\hline
\end{tabular}

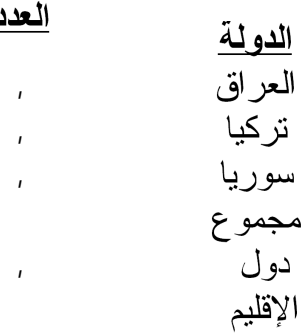

*المصدر :اعتمادأ على تقديرات سكان العراق لعام 0 . · r. أنظر إلى: جمهورية العراق، الجهاز

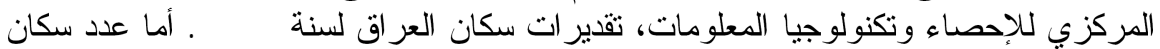

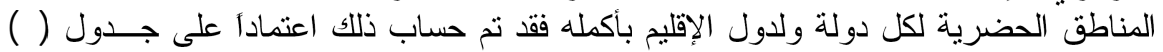
أدناه و على نسب السكان الحضر الو اردة في:

UN, Department of Economic and Social Affairs, World Urbanization Prospects: The 2005 Revision (UN Publications: 2006), Tables A.1 and A.2.

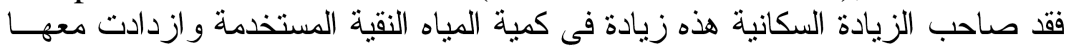

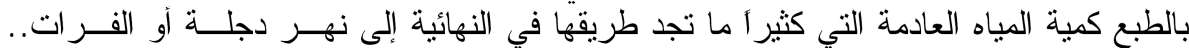

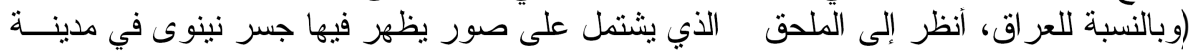
الموصل، الذي أنشئ في الثثلثينات من القرن الماضي الثئي ، ومصبين للمياه العادمة يزيد عمر أحدهما

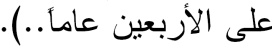

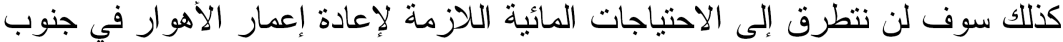

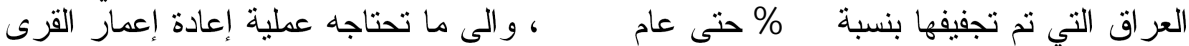

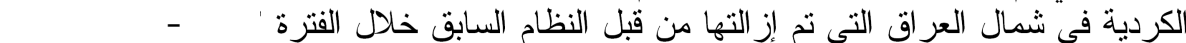

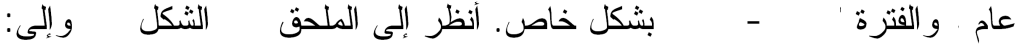


يوفرها نهري دجلة والفرات للدول الثالاث كهتلة سكانية واحدة ولكل دولة

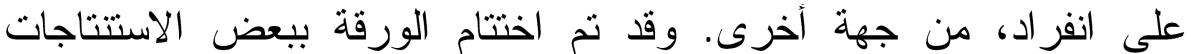
ومقترحين.

\section{(1) خطوط انتابيب صادرات النفط العراهي الخام عبر سوريا وتركيا وشيء عن الاستيرادات العراقيه من الدولتين:}

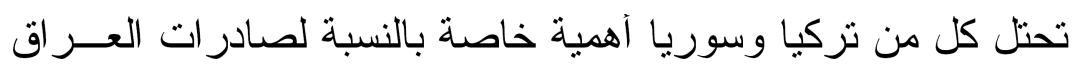

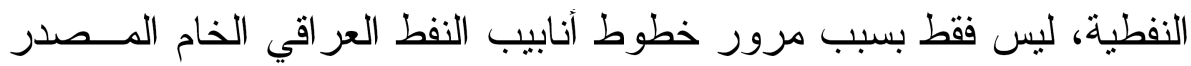
عبر أر اضيهما، بل لكون ثلثي منافذ صادر ات النفط الخام تقع على شوط الفي الفئهما

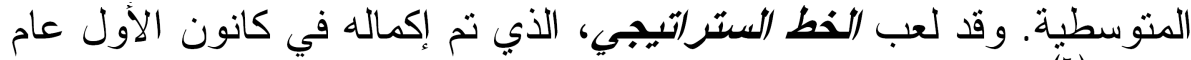
I9V0

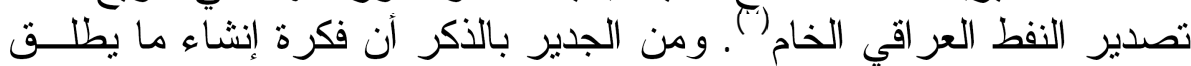

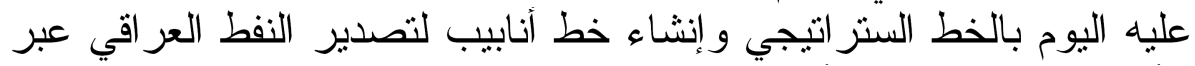

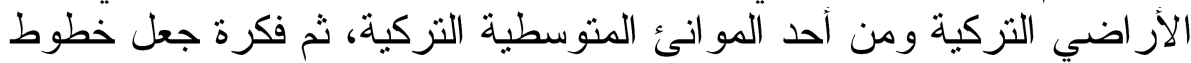

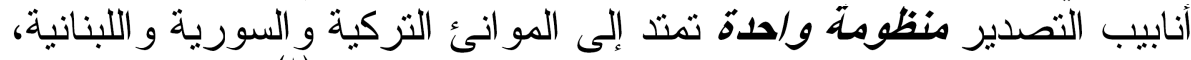

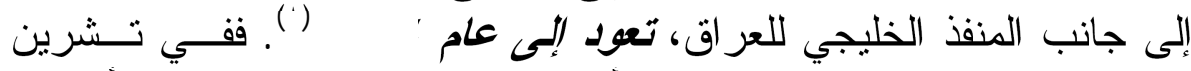

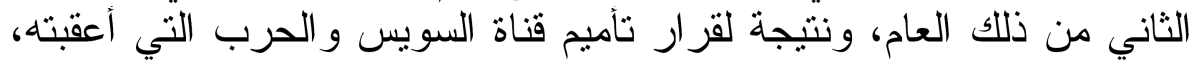

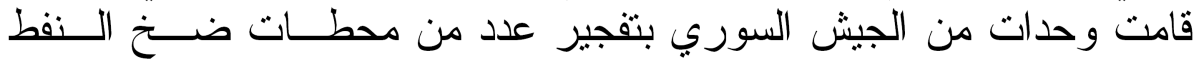

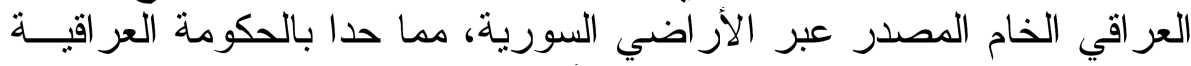

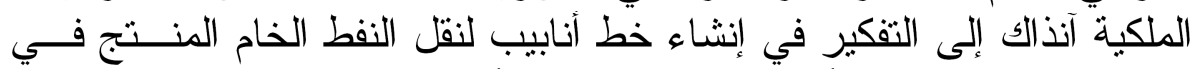
حقول كركوك، عبر الأراضي التركية، إلى أحد المو انئ المتوسطية التركية.

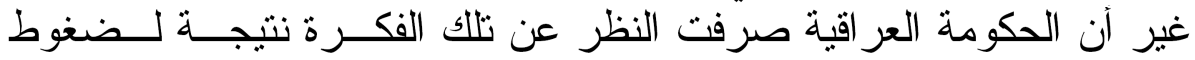

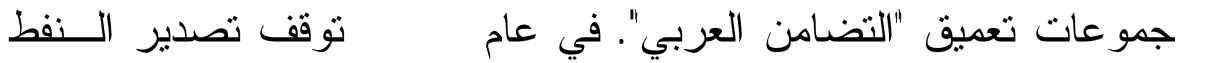

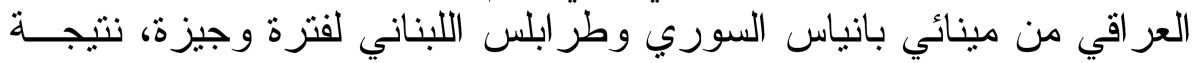

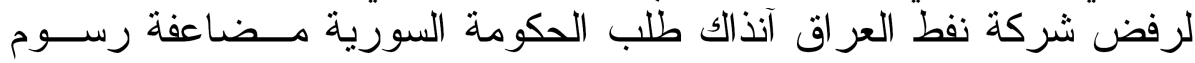

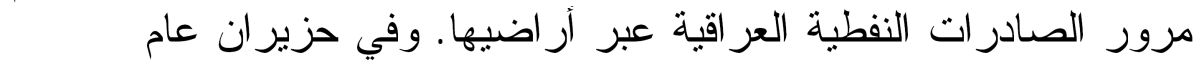

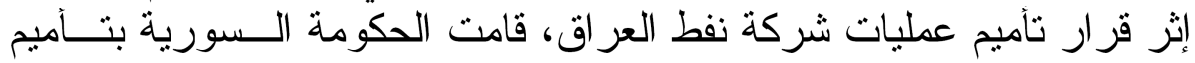

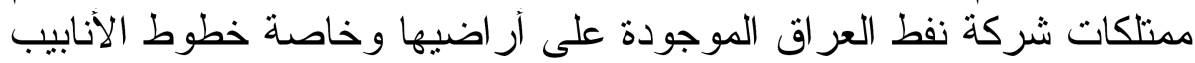

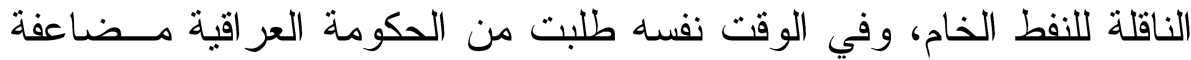

Rabil, R. G., "Operation Termination of Traitors' : The Iraqi Regime Throughout Its Documents", Middle East Review of International Affairs, Vol. 6, No. 3, September 2002 (file://A:I TERMINATION OF TRAITORS.htm). 


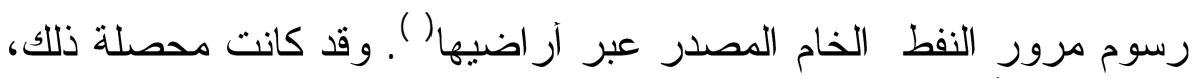

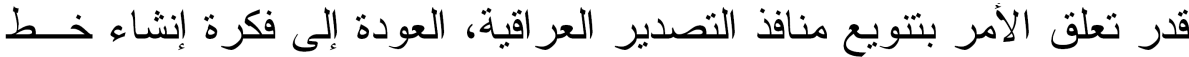

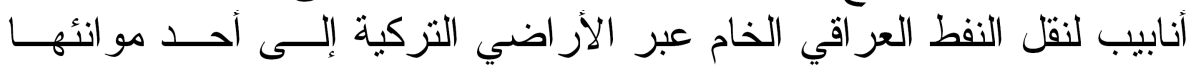

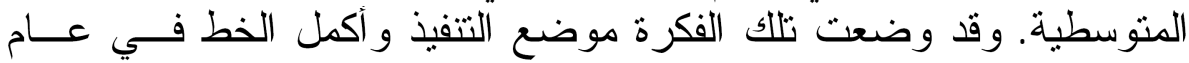

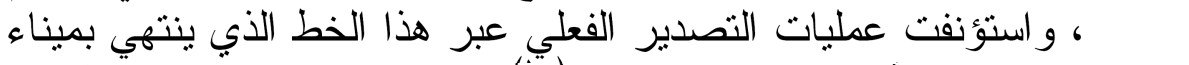

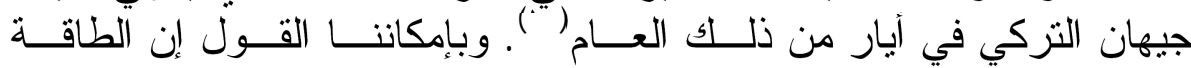

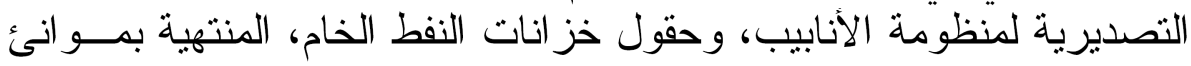

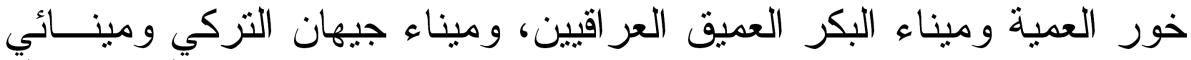

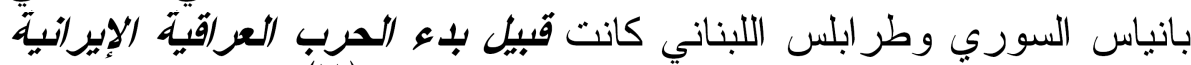

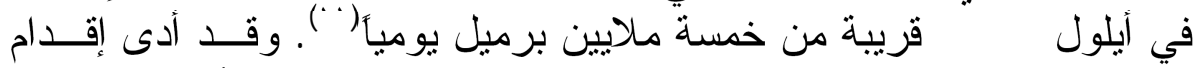

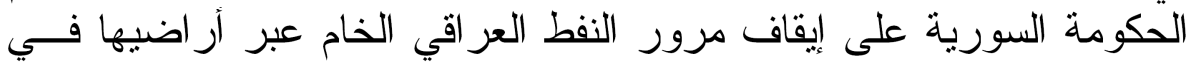

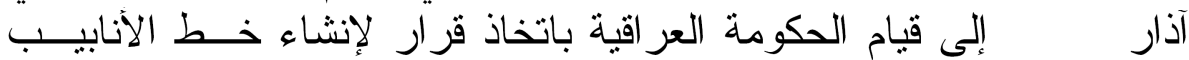

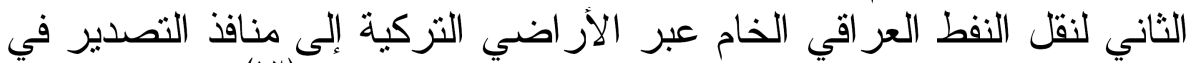

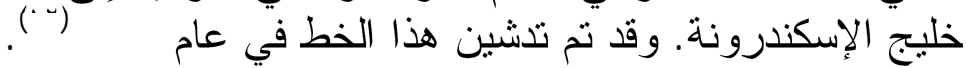

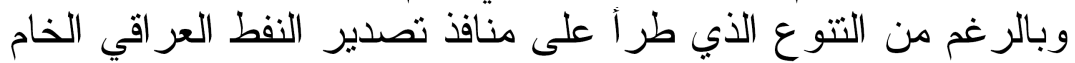

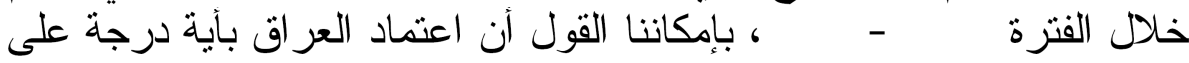

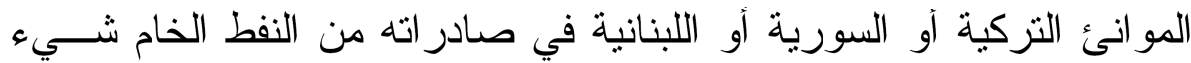

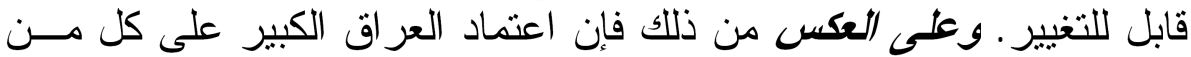

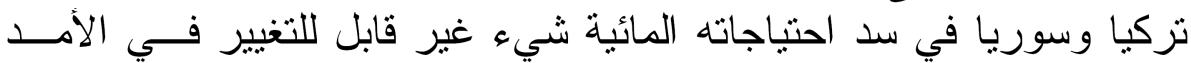
القصير أو الأمد الطويل. فيل.

وفيما يتعلق بجانب الاستير ادات العر اقية مما تتنجه تركيا أو ســوريا

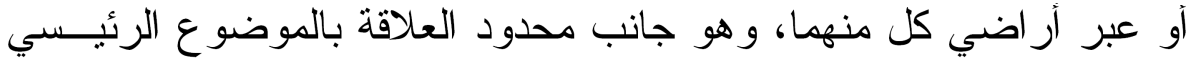

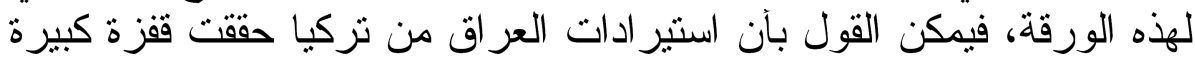

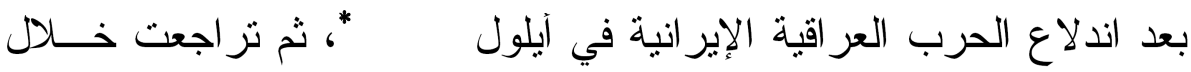

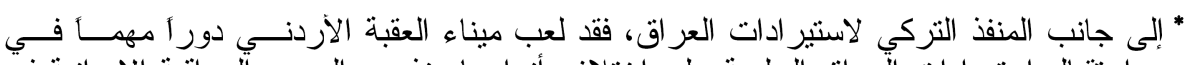

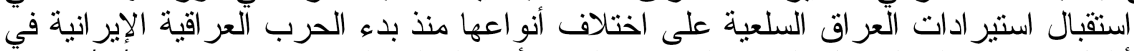

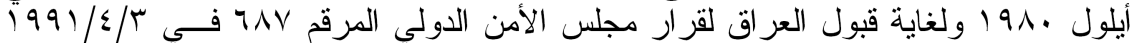

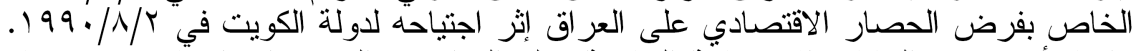

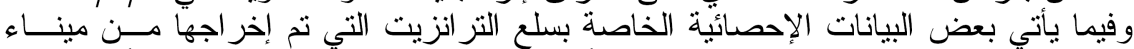

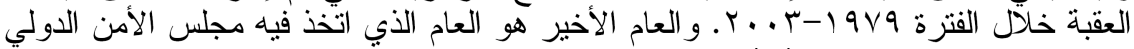

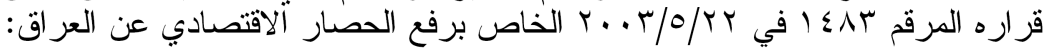




$$
\begin{aligned}
& \text { فتزة الحصار الاقتصـادي. أما استنير ادات العراق من سوريا، فيمكن القــول } \\
& \text { بأن تغير ها الكبير جاء منأخر آنسبياً. } \\
& \text { (1) النمو السكاني وي دول حوض دجله و القرات، القوى العاملاه وشيء } \\
& \text { عن الطاهه الإنتاجيه الزراعيه: }
\end{aligned}
$$

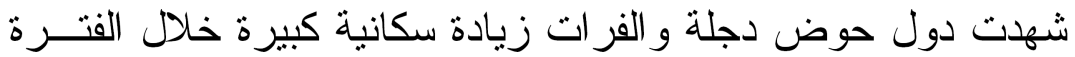

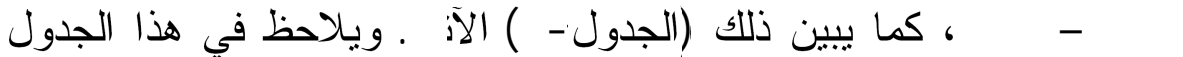

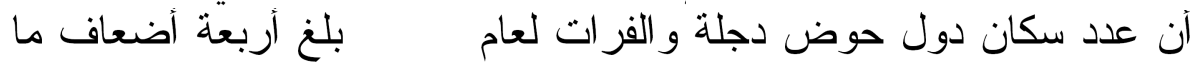

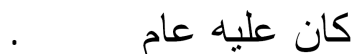

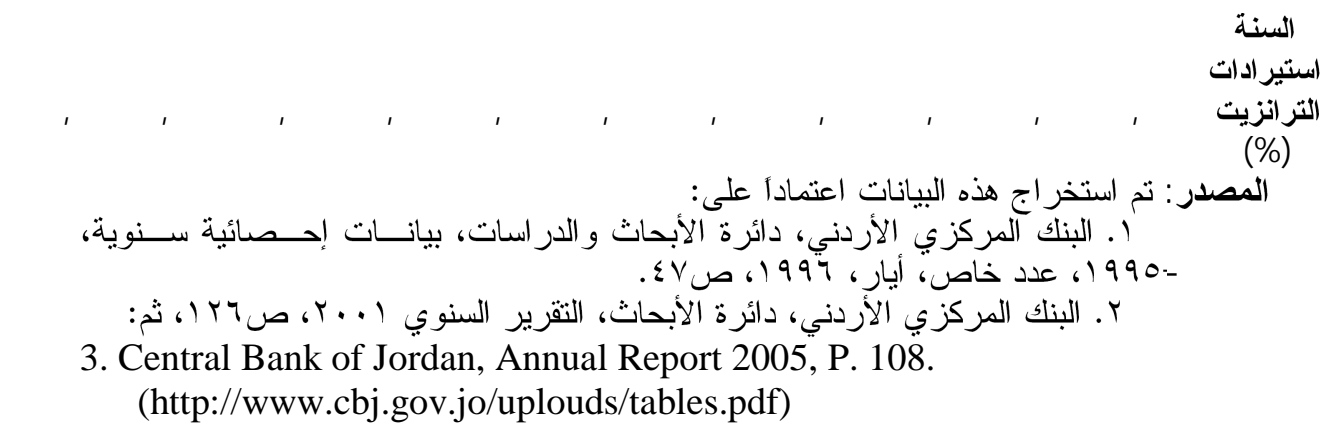

3. Central Bank of Jordan, Annual Report 2005, P. 108.

(http://www.cbj.gov.jo/uplouds/tables.pdf) 
[rv]

جدول ( 1): سكان دول حوض دجلة والفرات للسنوات 190، $19 v 0$ ،

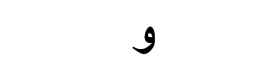

\begin{tabular}{|c|c|c|c|c|c|c|}
\hline \multicolumn{2}{|c|}{ المعدل السنوي للنمو (\%) } & \multicolumn{4}{|c|}{ عدد السكان (مليون نسمة) } & \multirow{2}{*}{ 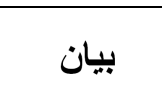 } \\
\hline$r \cdot .7$ & 1991/197. & $r \cdot .7$ & r... & $19 V 0$ & 190. & \\
\hline $1, V$ & $r, V$ & O & $\mathrm{I} \cdot \mathrm{V}, \Lambda$ & $09, \Lambda$ & $\mu$ & الإقليم \\
\hline$r, V$ & $r$ & $r \Lambda, \Lambda$ & $r \varepsilon, 9$ & 11,1 & $0, \mu$ & العر اق \\
\hline $1, r$ & $r, \varepsilon$ & $V \varepsilon, r$ & $77, V$ & $\varepsilon 1, r$ & $r \mid, 0$ & تركيا \\
\hline$r, r$ & $r, r$ & 19,0 & $17, r$ & $V, 0$ & $r, 0$ & سوريا \\
\hline
\end{tabular}

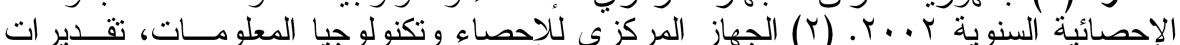

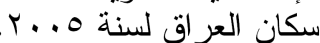

(3) UN, World Population Prospects, The 2004 Revision Of Population Data

Base (http://csa.un.org/unpp); UN, Department Of Economic \&Social Affairs, Indicators On Population.

http://unstats.un/indicators/und/demographic/products/socind/production.htm

وبالرغم من الانخفاض الملحوظ الذي طر آ على معدل النمو السكاني

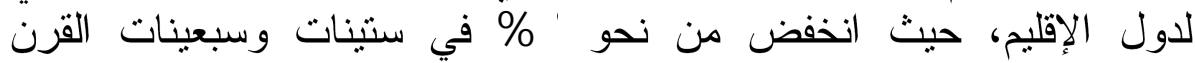

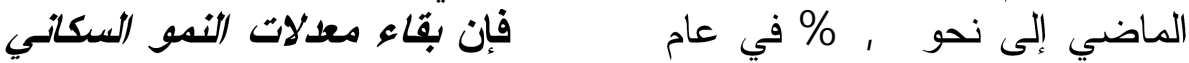

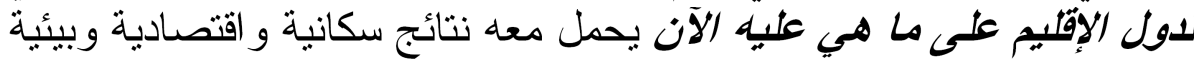
خطيرة. من هذه النتائج: (1) خلال خمس سنوات من الآن بتوقع آن بزداد عدد سكان دول الإقليم بما

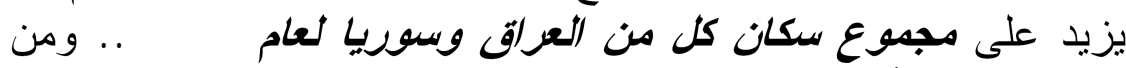

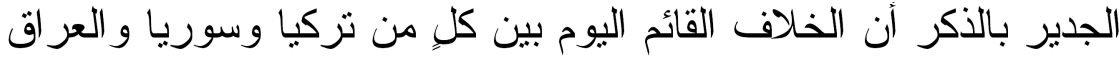

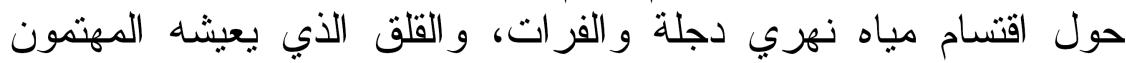

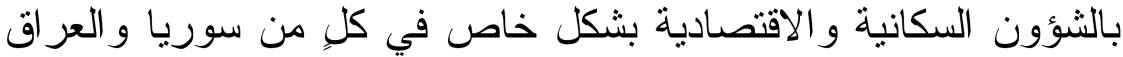

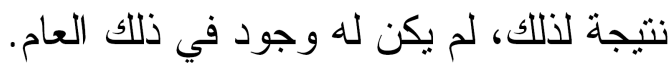

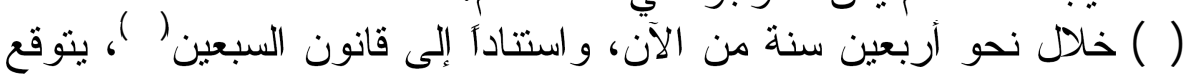

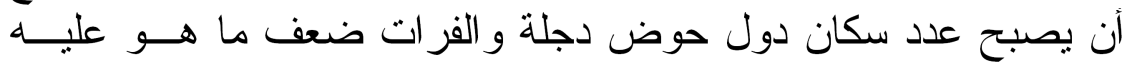

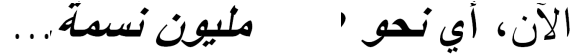




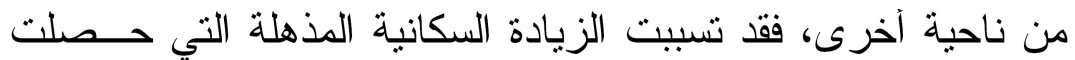

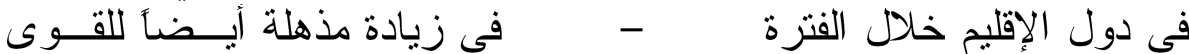

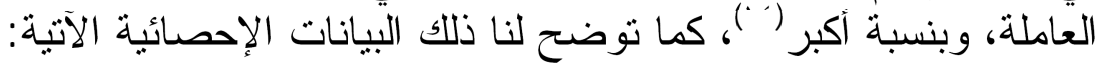

جدول (1): القوى العاملة لاول حوض دجلة و الفرات للسنوات 190، r. . . I9vo

\begin{tabular}{|c|c|c|c|c|}
\hline r.. T & r... & $19 V 0$ & 190. & السنة \\
\hline$\varepsilon V, \Lambda$ & $\varepsilon r, \mu$ & $r \cdot, \mu$ & $1 \cdot, \varepsilon$ & لقوى العاملة (مليون شخص) \\
\hline
\end{tabular}

UNDP, Human Development Report 1993, P. 168; UNDP, Ibid., 1998, PP. 164-165.

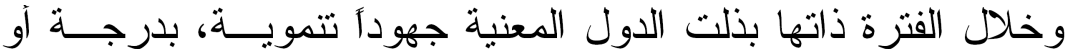

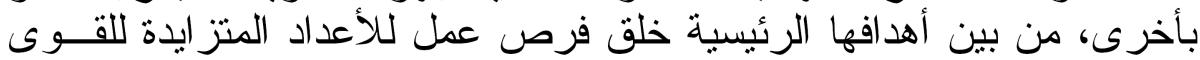

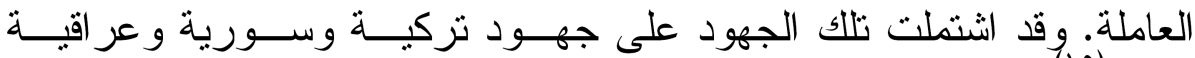

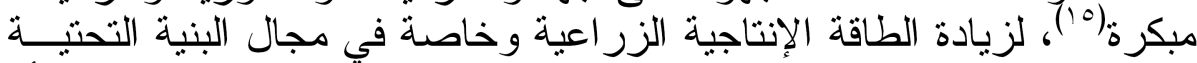

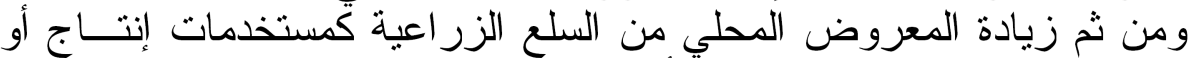

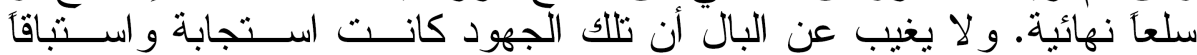

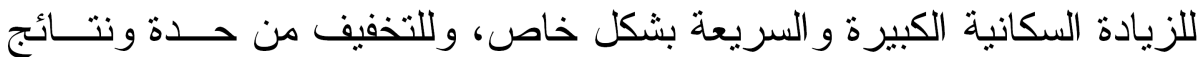

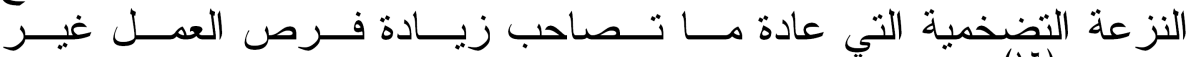

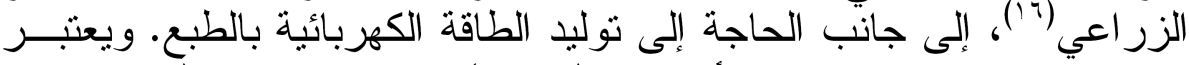

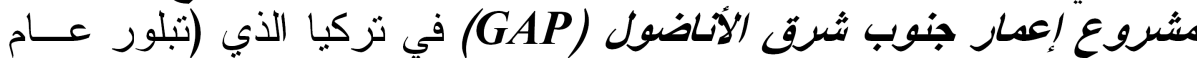

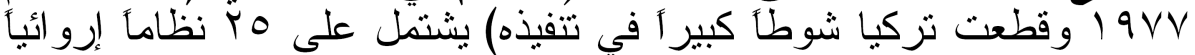

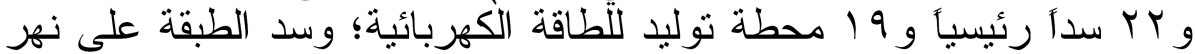

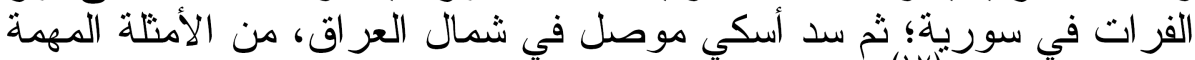

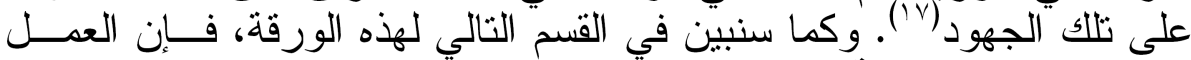

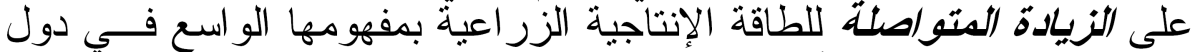

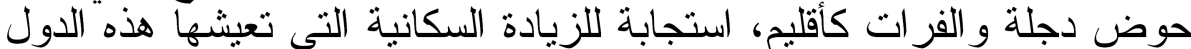

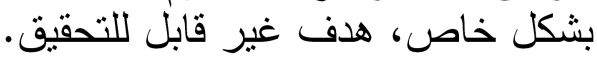

(r) النمو السكاني والنمو الزراعي وكميه المياه المتاحه وي نهري دجله

$$
\text { و الفر ات }
$$

في القسم الأول لهذه الورقة آثنبر إلى أن اعتماد العراق على المنافذ

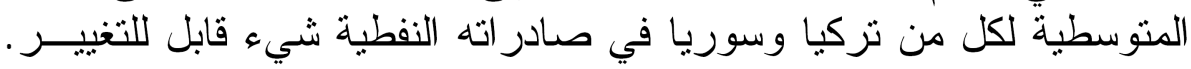

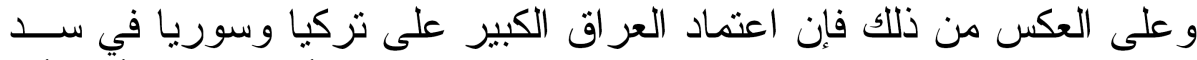

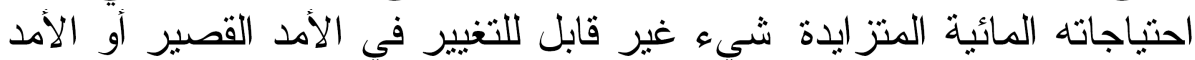

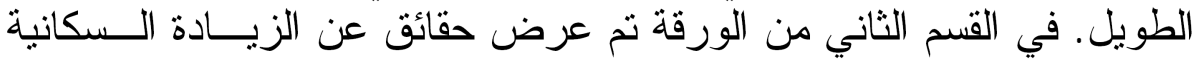




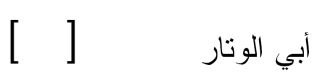

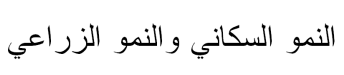

التي شهدتها وتشهدها دول حوض دجلة و الفرات. كما نم التطرق إلى الزيادة

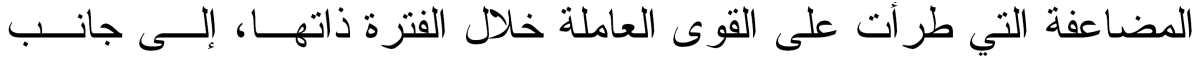

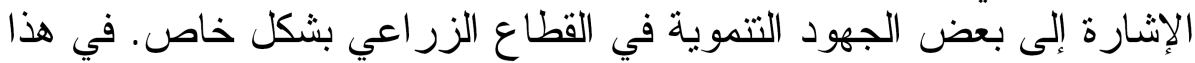

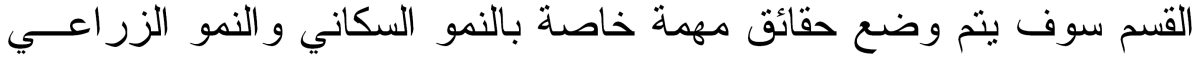

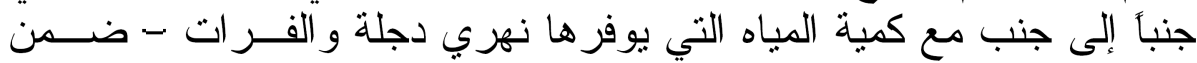

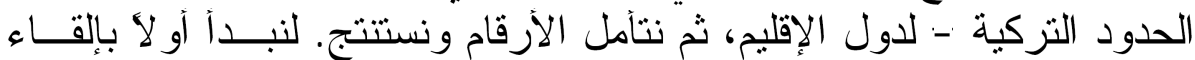

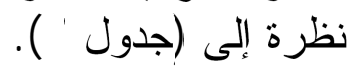

إن البيانات الإحصائية الواردة في الجدول أعلاه، مرتبة بطريقة تقود

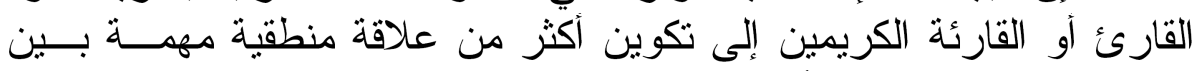

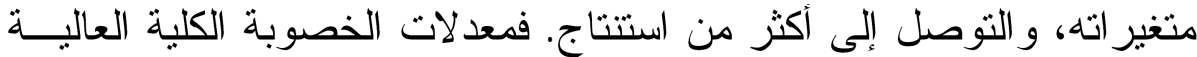

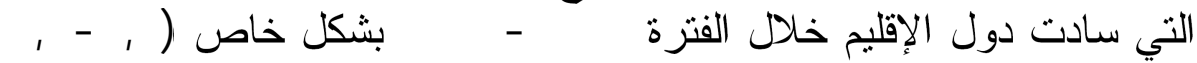

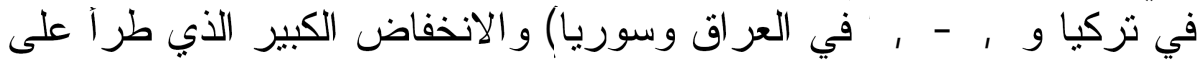

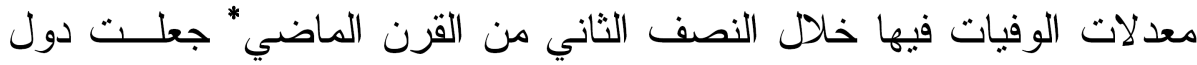

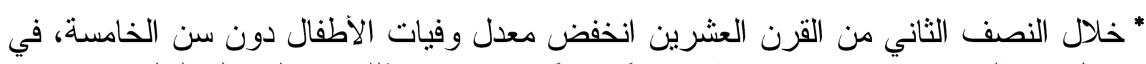

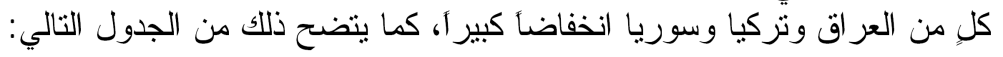

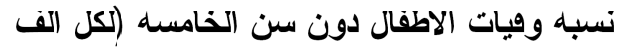

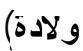

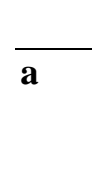

197.

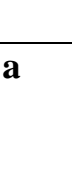

$1 \% 9$

الدولة

17

19.

العر اق

تركيا

1 ro

سور

l.

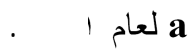

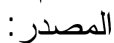

UNDP, Human Development Report 2006, PP. 316-317; UNDP, Ibid., 1993, P. 142.

نتيجة لذلك، و لأسباب أخرى، فقد استقبلت دول حوض دجلة و الفرات الألفية الثالثة بمعدل للمو اليد يزيد على ثلاث أضعاف معدل الوفيات.. أنظر على سلى سبيل المثال إلى:

UN, Department off Economic and Social Affairs, Demographic Yearbook 2003, Table 4: 
الإقليم تعيش حالة من الانفجار السكاني نقلت عدد سكان دول الإقليم من نحو

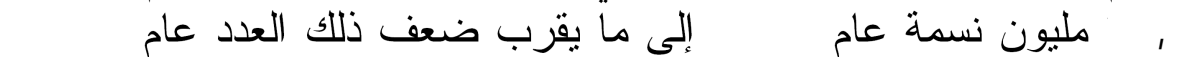

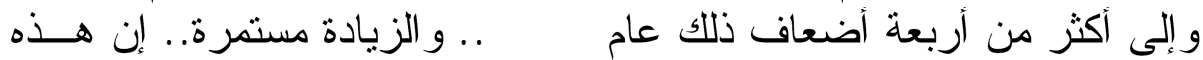

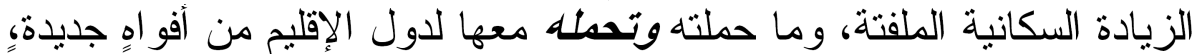

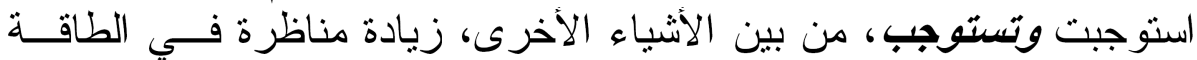

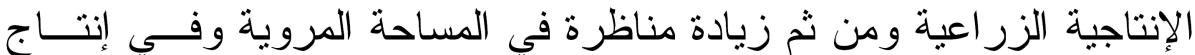

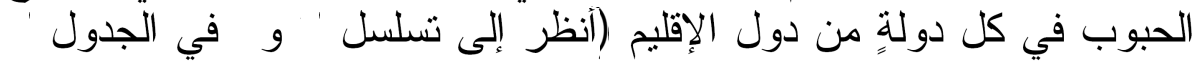
أعلاه). كل ذلك حدث ويحدث في ظل معدل سنوي كلي ثابت نسبياً للمو ارد الته

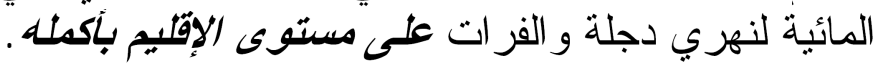

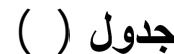

بيانات ديموغر افية، المساحة المروية و إنتاج الحنطة والحبوب، والمات والموارد

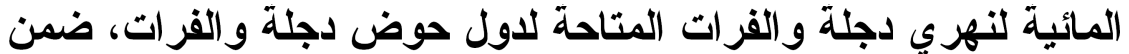
الحدود التركية لسنوات مختارة

\begin{tabular}{|c|c|c|c|c|c|}
\hline r.. T & r... & $19 V 0$ & 190 . & بيان & $ت$ \\
\hline 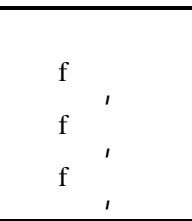 & 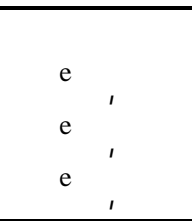 & $\begin{array}{l}{ }^{c} V, \\
{ }^{d} 0, r \\
{ }^{d} V, 0\end{array}$ & $\begin{array}{l}{ }^{b} \mathrm{~V}, \mathrm{l} \\
\mathrm{b} 7, \varepsilon \\
\mathrm{b} v, r\end{array}$ & 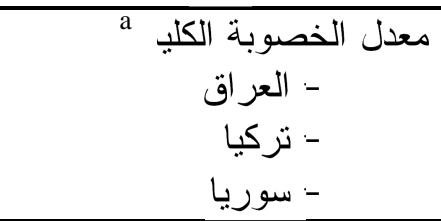 & 1 \\
\hline $1 Y r, 0$ & $1 \cdot V, \Lambda$ & 09,1 & $\mu \cdot \mu$ & السكان (مليون نسمة) & $r$ \\
\hline 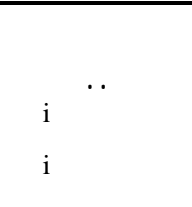 & $\begin{array}{l}\text { roro } \\
\text { h EVEr } \\
\text { h וrr }\end{array}$ & $\begin{array}{l}1077 \\
\text { g rVIr } \\
\text { or. }\end{array}$ & $\begin{array}{l}. . \\
. . \\
. .\end{array}$ & الازر - - اضي العروية (آلف هكتار) & $\mu$ \\
\hline 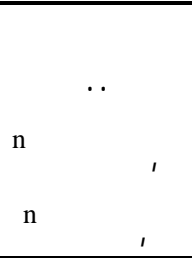 & 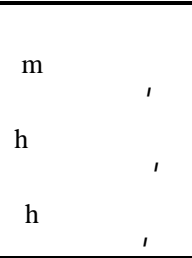 & 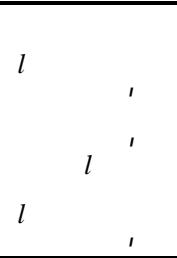 & $\begin{array}{c}\text { k IV£१,V } \\
\text { VVาศ, } \\
\text {.. }\end{array}$ & إنتاج الحبوب (ألف طن) - العراق - & $\varepsilon$ \\
\hline $\begin{array}{c}\cdots \\
{ }^{n} r \cdots \varepsilon, \cdot \\
{ }^{n} \varepsilon V r o, \cdot\end{array}$ & $\begin{array}{l}\text { m oor,0 } \\
\text { h } 19 \mu \varepsilon 1, \mu \\
\mu \text { I.0,0 }\end{array}$ & 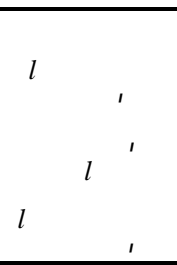 & $\begin{array}{l}\text { Vrר,r } \\
r \wedge V r, \cdot \\
{ }^{\circ} \wedge \varepsilon \varepsilon, \wedge\end{array}$ & إنتاج الحنطة (آلف طن) - العراق - & 0 \\
\hline 00 & 00 & 00 & 00 & معدل التدفق السنوي لمياه دجلة & 7 \\
\hline
\end{tabular}

http://unstats.un.org/unsd/demographic/products/dyb/dyb2.htm 


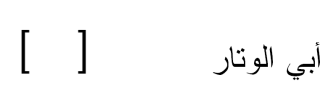

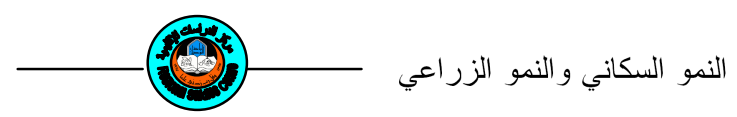

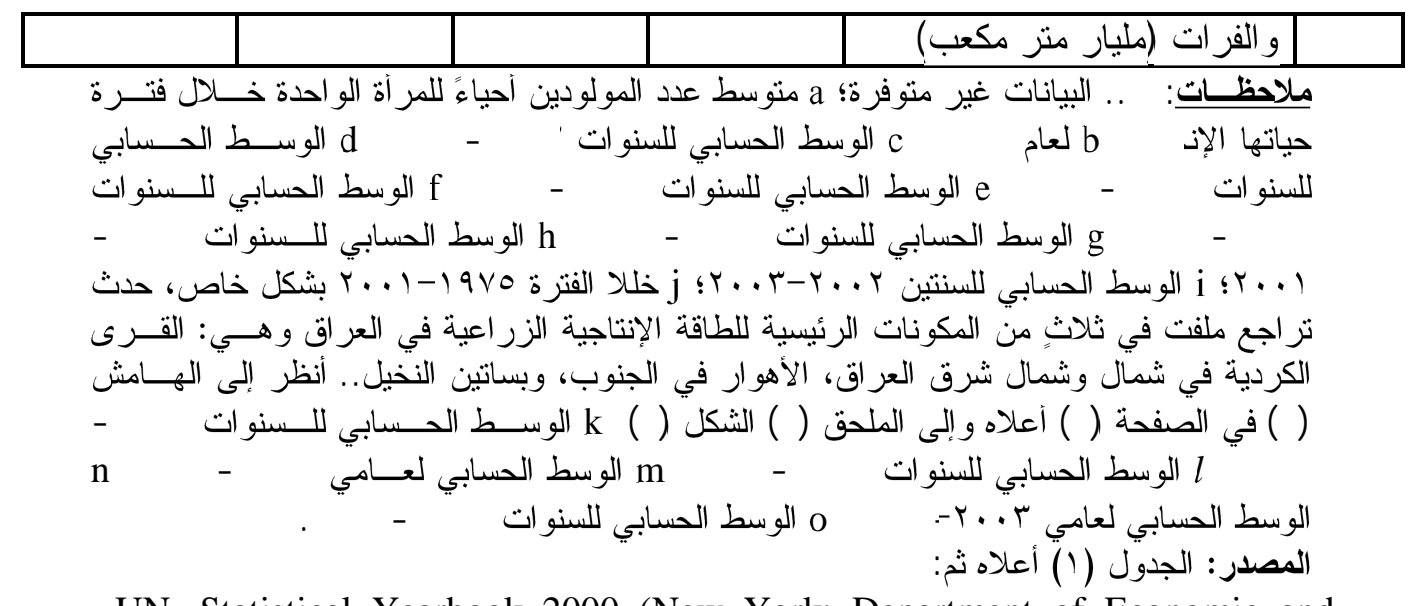

UN, Statistical Yearbook 2000 (New York: Department of Economic and Social Affairs), earlier issues; UN, Economic and Social Commission for Western Asia (ESCWA), Statistical Abstract of the ESCWA Region 2003, earlier issues; UNDP, Human Development Report 2006, earlier issues; FAO, The Statistics Division, Compendium of Food and Agricultural Indicators 2006 (http://www.fao.org/statistics/compendium_2006/defult.asp); FAO, Indicator Tables (http://faostat.fao.org/site/339/default.aspx); Richter, et. al., Ibid., P. 178; Singer, Ibid., P. 105, 214, and 236; Kundell, J., (ed.), "Water Profile of Turkey", Encyclopedia of Earth, 2006, Update Feb.2007 (http://www.eoearth.org/article/Water_profile of Turkey).

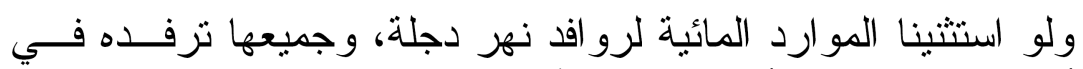

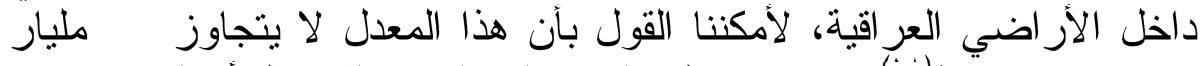

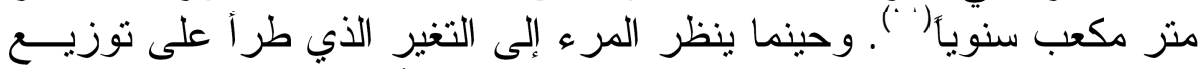

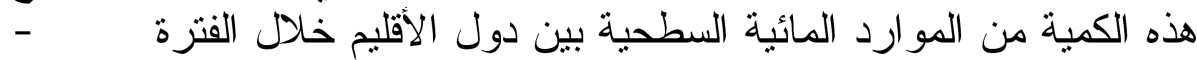

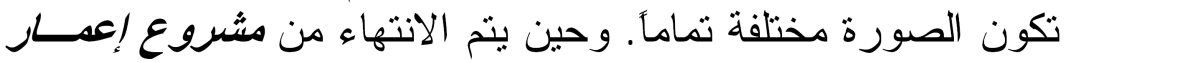

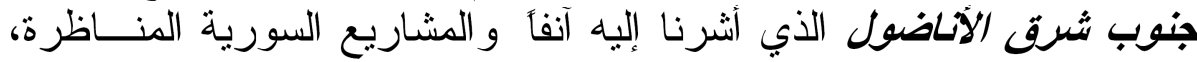
تصبح الصورة أكثر اختلافأ...

فوفقاً للاتفاق الذي وقع بين الحكومنين التركية و السورية في تمــوز ع 19 1 V

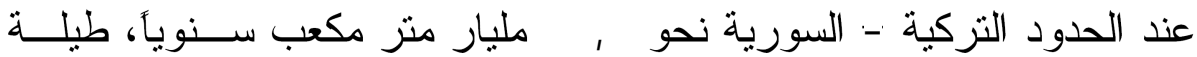

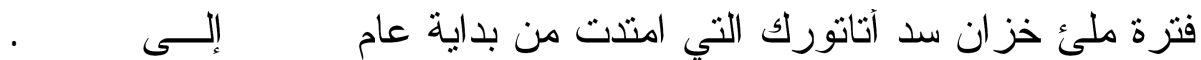


بعد ذلك أصبح المعدل المناظر نحو بr مليار مثر مكعب سنوياً. وبالنـسبة

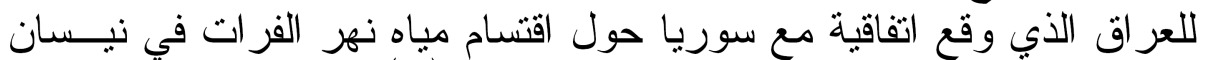

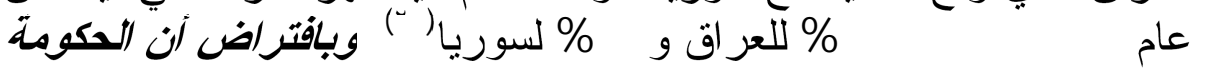

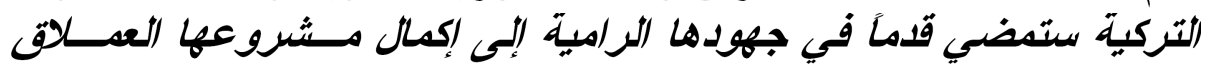

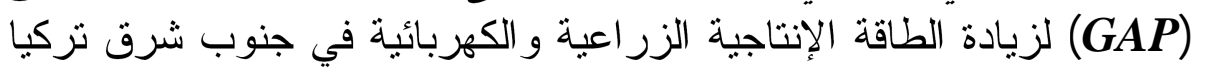

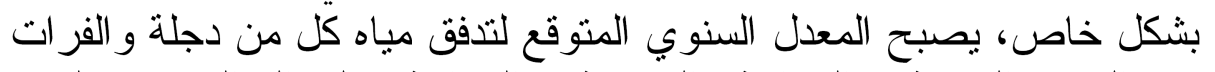

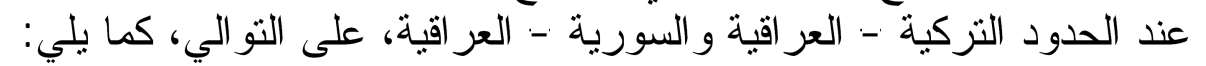
11,0 مليار منز مكعب سنوياً لنهر دجلة.

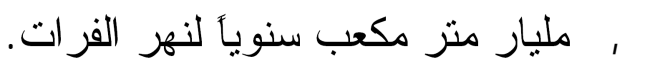

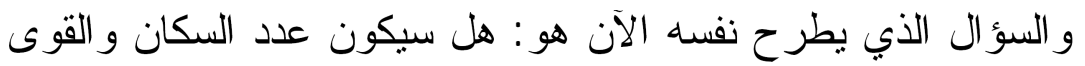

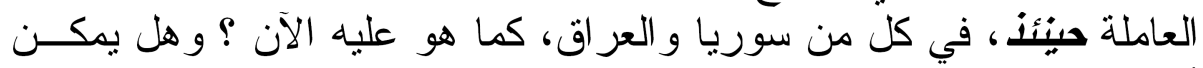

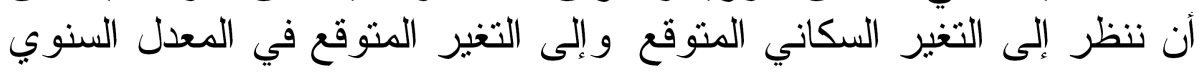

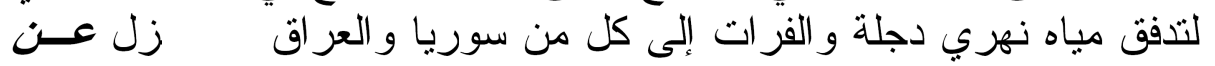

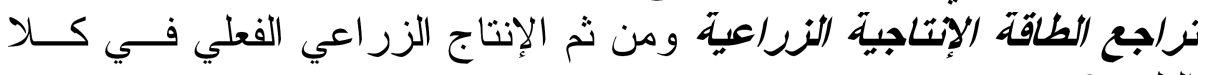

\section{(ع) بعض الاستتتاجات ومقترحين.}

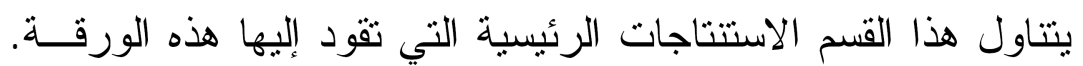

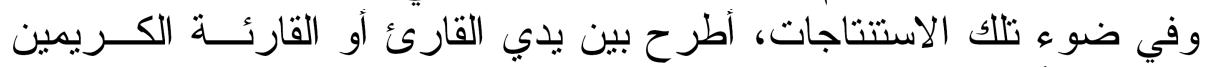

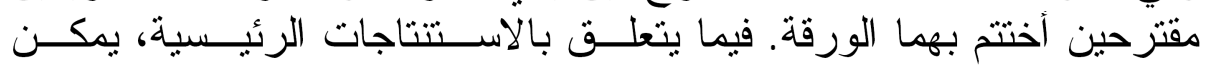
تلخيصها بما ياتي: الزئين

ا ـ إن الزيادة السكانية الكبيرة التي شهدتها دول حوض دجلة و الفرات خلال

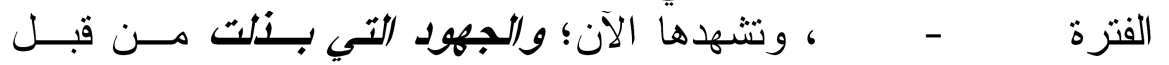

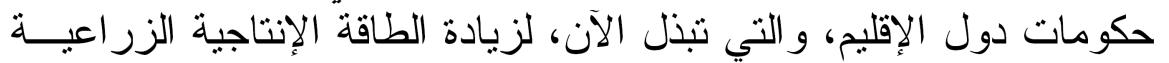

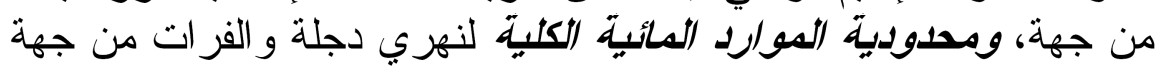

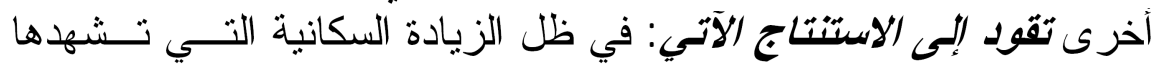

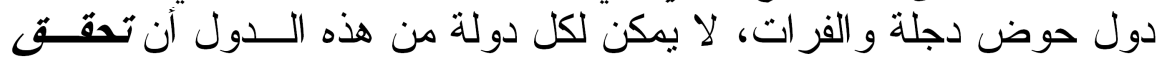

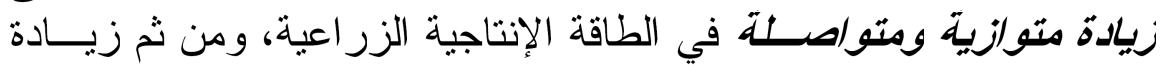
مناظرة في الإنتاج الزر اعي الفعلئ

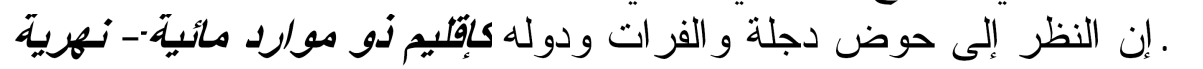

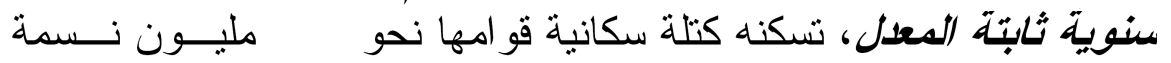

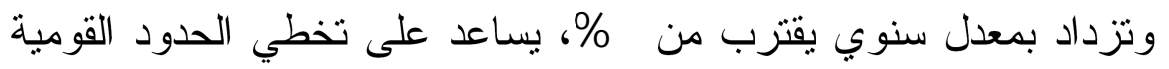

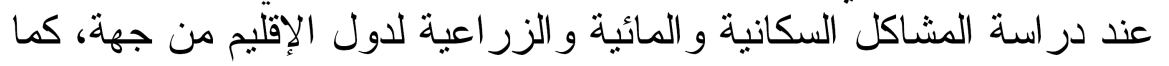


[rr]

يساعد على زرع روح التعاون بين الأطر اف لحلها بأسلوب علمي، مـن

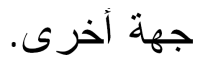

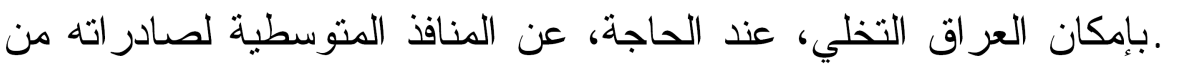

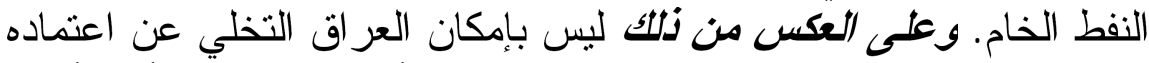

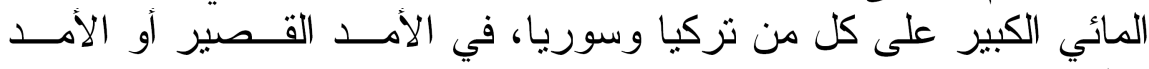

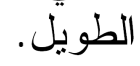

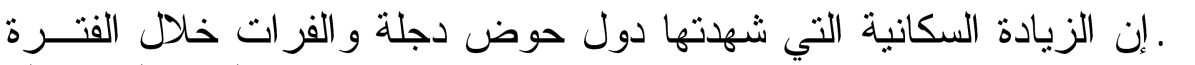

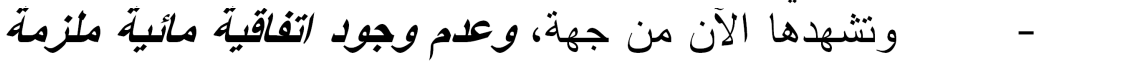

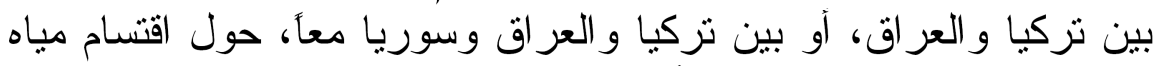

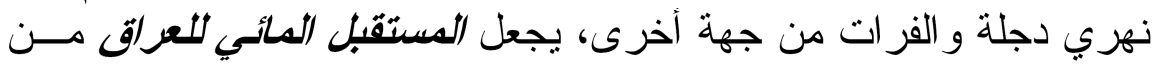

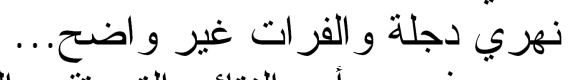

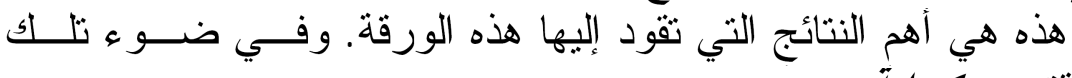

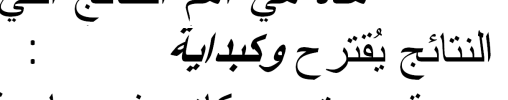

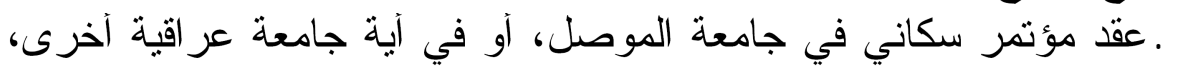

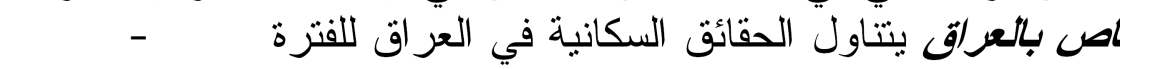

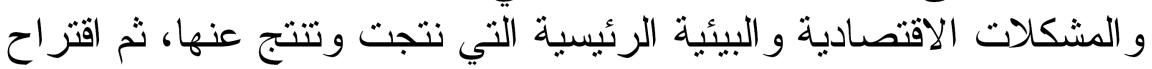

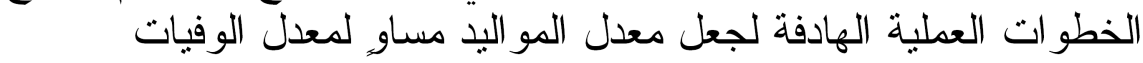

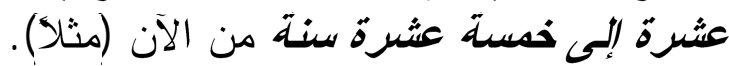

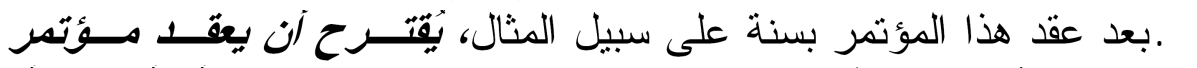

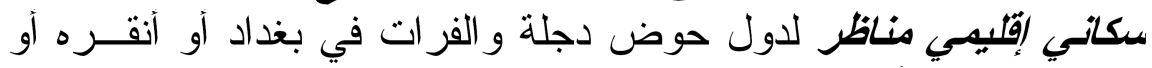

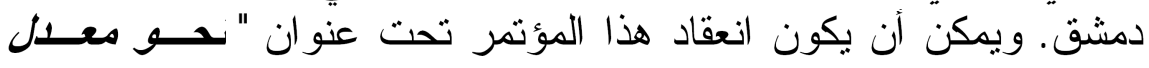

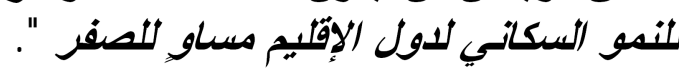
هذا ما وددت تقديمه في هذه الورقة البحثية، و الله ولي التوفيق. الوبى الوتار $r \cdot \mathrm{v} / \mathrm{v} / \mathrm{rT}$ 


\title{
Population Growth And Agricultural Growth Under Limited Surface Water Resources In The Tigris-Euphrates Basin States: 1950-2006
}

\author{
Obey M. Al-Wattar \\ Ph. D. Econ., Southampton University, UK. \\ Econamics Department, Faculty of Administration \& Econamics, \\ Mosul University, Irag
}

\section{Abstract}

Over the period 1950-2006, the Tigris-Euphrates basin states (i.e. Iraq, Syria and Turkey) witnessed an alarming population growth. During that period, the region's population increased from $\boldsymbol{\mu} \cdot \boldsymbol{\mu}$ million in 1950 to more than 120 million in 2006. Moreover, population growth in the region is currently (2007) at an absolute rate of more than two million a year. Parallel to this population growth, in response to and in anticipation of the rapidly increasing population size in particular, the governments of the region made a large-scale developmental efforts. These efforts included a large-scale investment in agricultural infrastructure, especially in the creation of irrigation capacities. All these efforts were conducted under a given average annual rate of flow of water resources, of Tigris-Euphrates rivers within Turkey, of some $\mathbf{5 5}$ billion cubic meter. This paper presents some facts on the changing population size (and labour force) in the Tigris-Euphrates basin states, as well as some facts related to agricultural growth in each over the period 1950-2006. The logical relationship among population growth, agricultural capacity expansion, and the given average annual rate of flow of surface water resources of the Tigris-Euphrates rivers (within Turkey) led the author to the following conclusion: population growth in the region is incompatible with the simultaneous and sustainable expansion of agricultural capacity in each of Tigris-Euphrates basin states. The author concluded this exploratory study by suggesting the organization of two consecutive conferences on population growth, past and present, in Iraq and in the region as a whole respectively. The aim of each is to formulate a united population policy aiming at the achievement of the 'zero population growth' target in the region, within ten to fifteen years.

Keywords: Tigris-Euphrates basin, basic economic relations, strategic pipeline, population growth, labour force, surface water resources, average annual flow, irrigated land, cereal production, water agreement, agricultural productive capacity. 
[ro]

$$
\text { أبي الونار }
$$

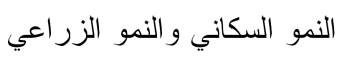

\section{ملحق}

الثكل (1): الشبكه الرئيسيه لخطوط انابيب نفل النفط العراهي الخام من مراكـز الإنتاج إلى منامد التصدير في راس الخليج، تركيا، وسوريا، إلــى جاتسب عــد

Zầkho

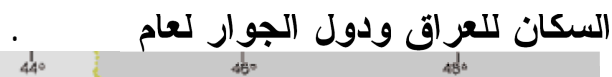

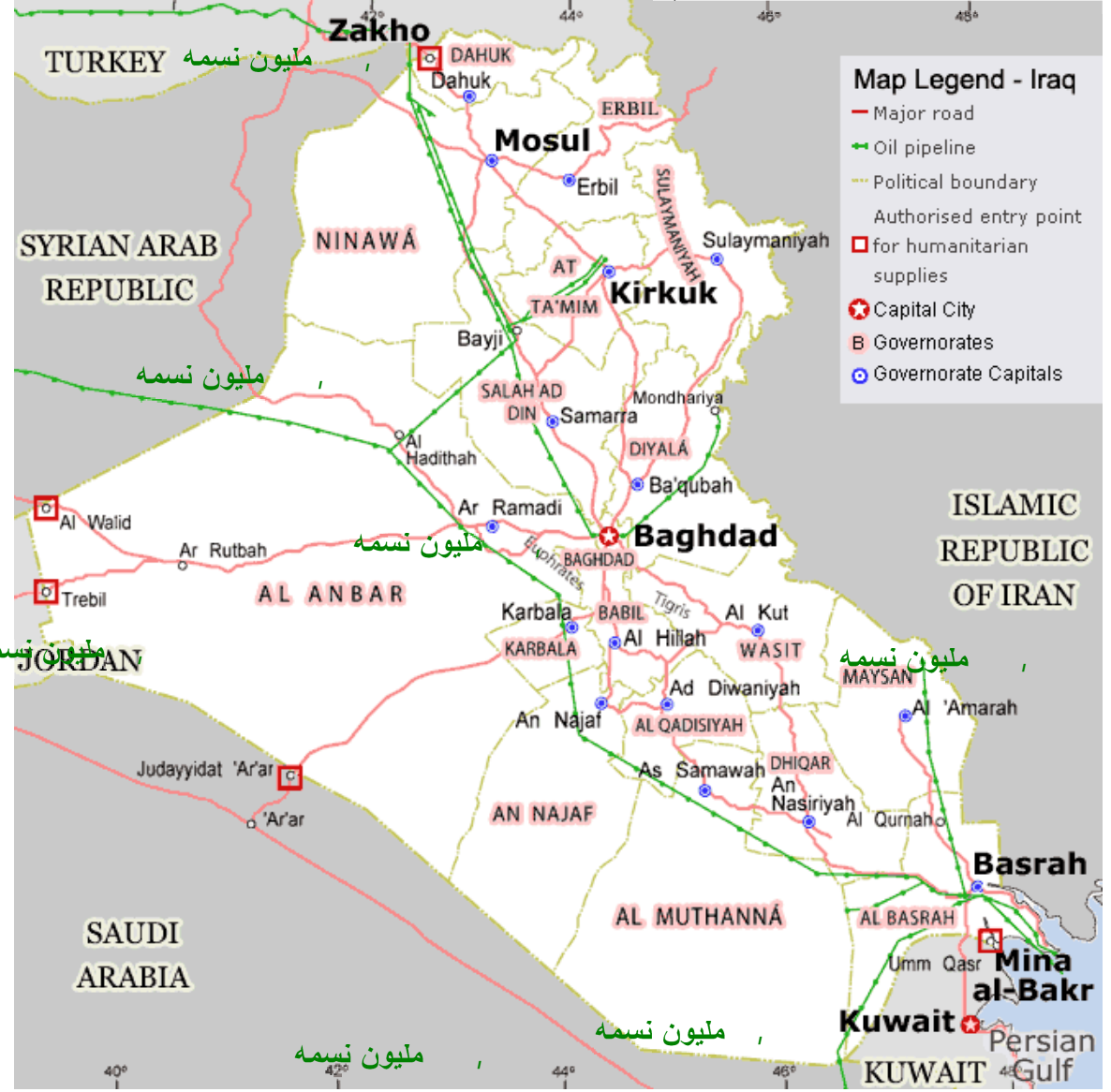

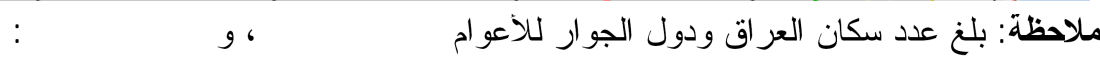




\begin{tabular}{|c|c|c|c|}
\hline \multicolumn{3}{|c|}{ عدد السكان (مليون نسمة) } & \multirow{2}{*}{ الاولة } \\
\hline ד.:. & $19 v 0$ & 190. & \\
\hline & 11,1 & $0, \mu$ & العر اق \\
\hline & $\varepsilon 1, r$ & $r I, 0$ & تزركيا \\
\hline كما في & س س, & 16.0 & إير ان \\
\hline الخارطة & 1, & $\cdot r$ & الكويت \\
\hline آعلاه & $\mathrm{V}, \boldsymbol{\mu}$ & r & 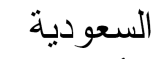 \\
\hline & 1,9 & $\cdot, 0$ & الأردن \\
\hline & $\mathrm{V}, 0$ & ए,0 & 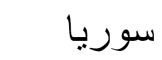 \\
\hline 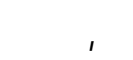 & $1 \cdot \mu, \mu$ & 50.2 & 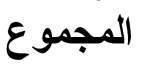 \\
\hline
\end{tabular}

UNDP, Human Development Report 2006; UN, Department of Economic and Social Affairs, World Urbanization Prospects: The 2005 Revision (UN Publications: 2006), Tables A.3 and A.4 (for the calculation of 1950 population data for Jordan, Kwait, and Saudi Arabia).For Iran's population in 1950 , see: Brown,L.R.and Kane,K. Full House,Worldwatch Environmental Alert Series(London: Norton\&Company,1994), P.59.

\section{الشكل (r): اعالي نهري دجله و الفرات في تركيا.}

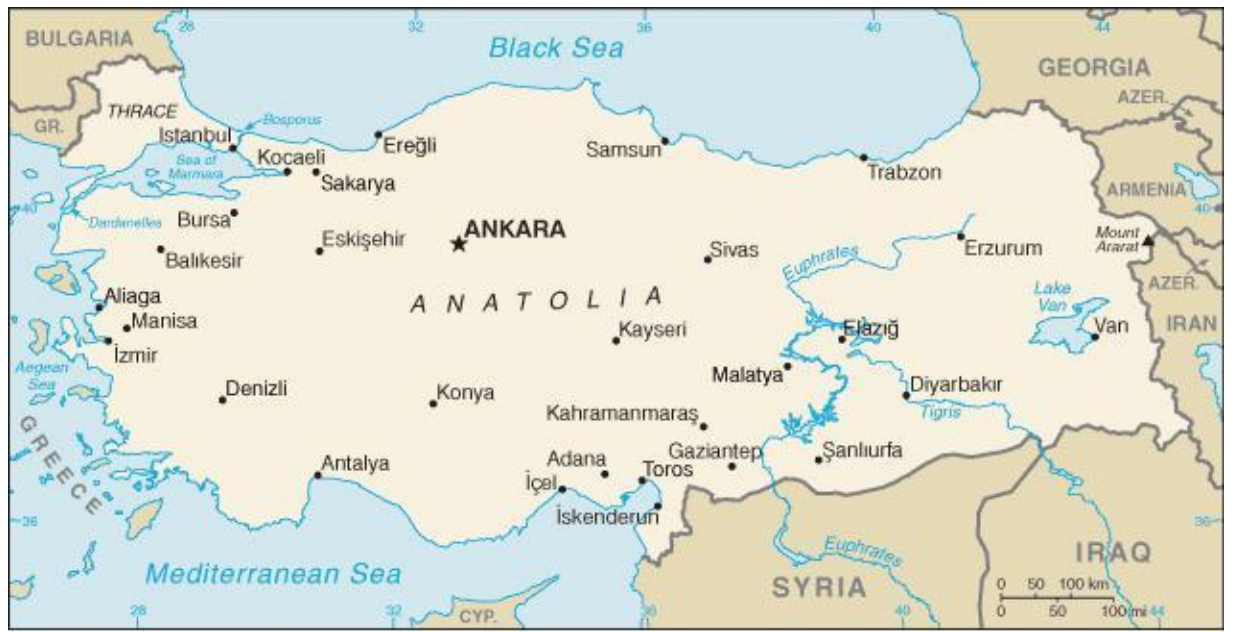

Source: Kundill, J. (ed.), "Water Profile of Turkey"

(http://www.eoearth.org/article/water_profile_a_Turkey), Internet update, February 8, 2007. 


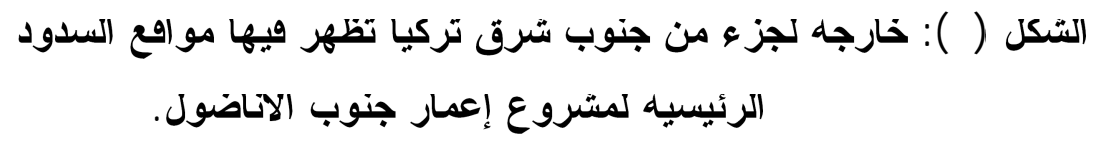

Dam Locations within the Southeastern Anatolia Project (GAP)

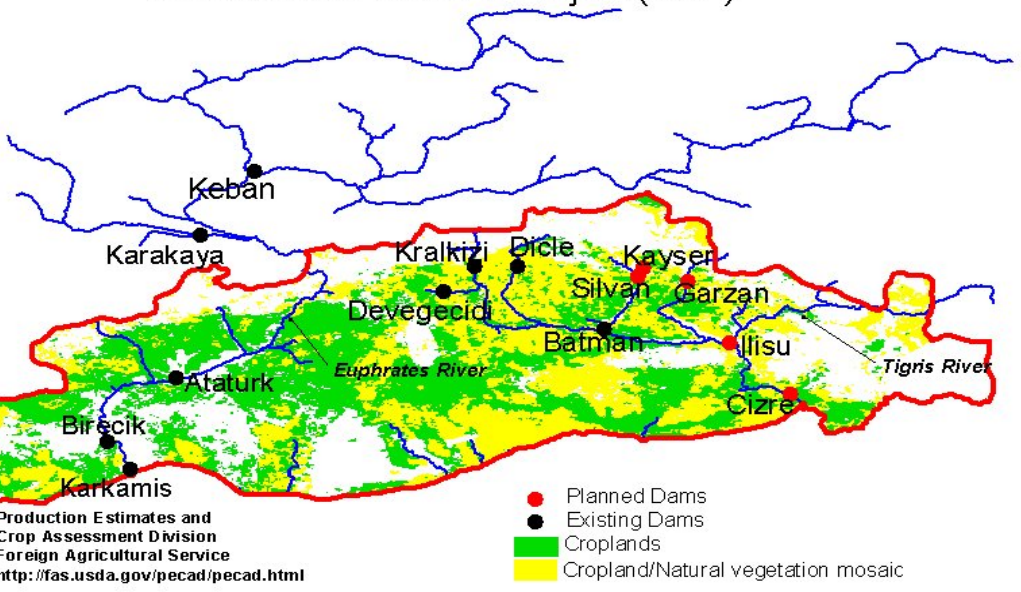

الشكل (ع): نهر الفرات في سوريا وتظهر فيه بحيرة سد الطبفه.

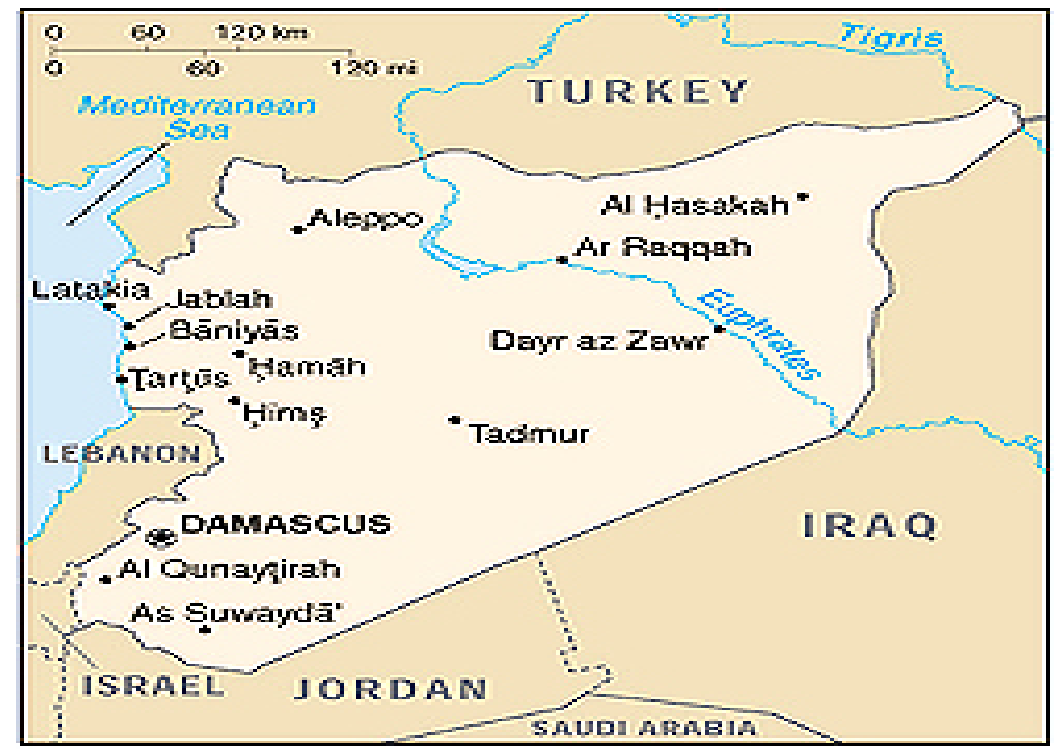




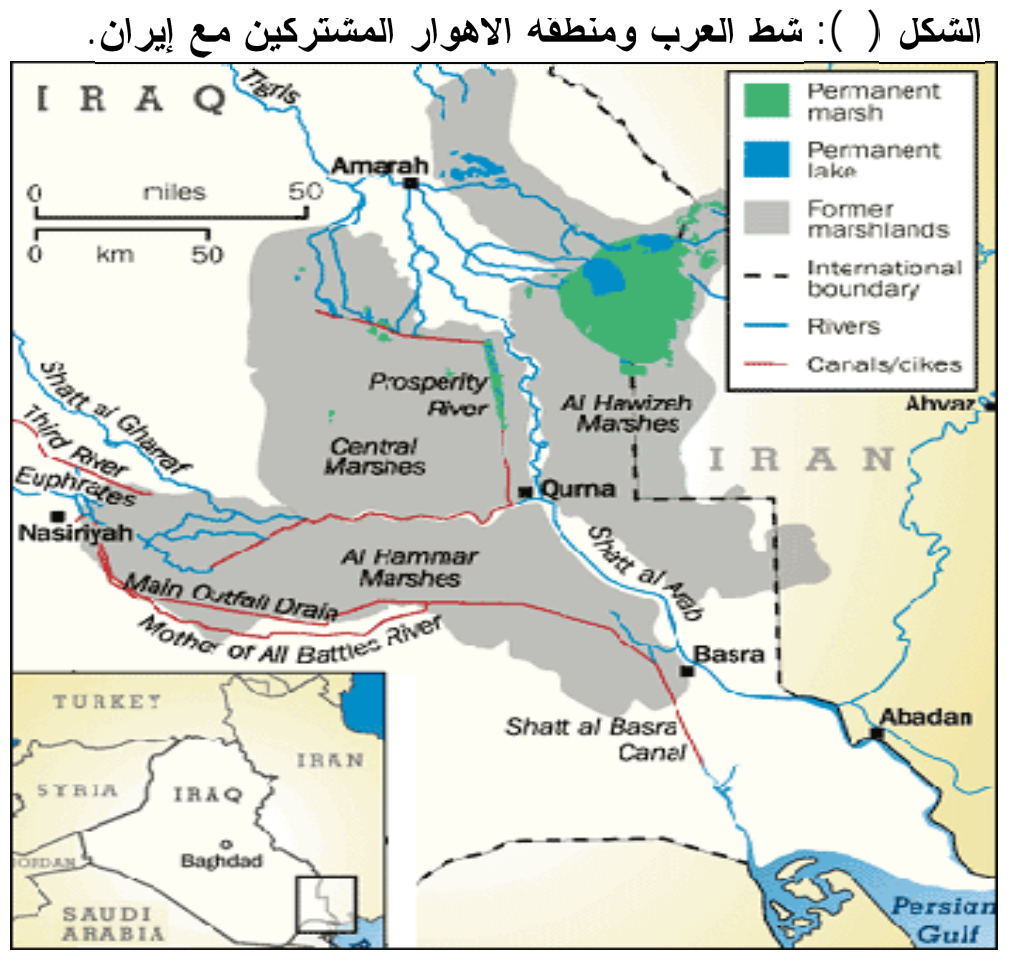

Source: UNEP Report "The Mesopotamian Marshland: Demise of An Ecosystem" (2001).

\section{ملحق (r)}

صور لجسر نينوى في مدينه الموصل ومكب للمخلفات الصلبه ومصبان للمياه

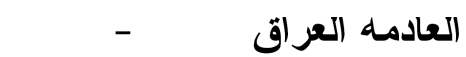

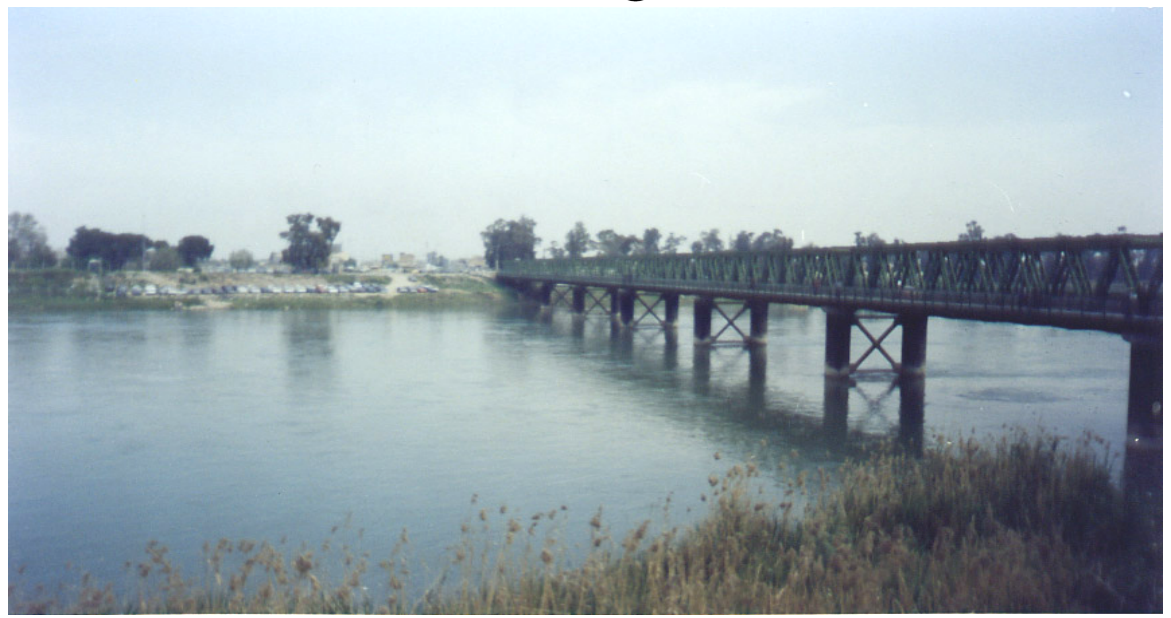




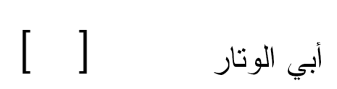
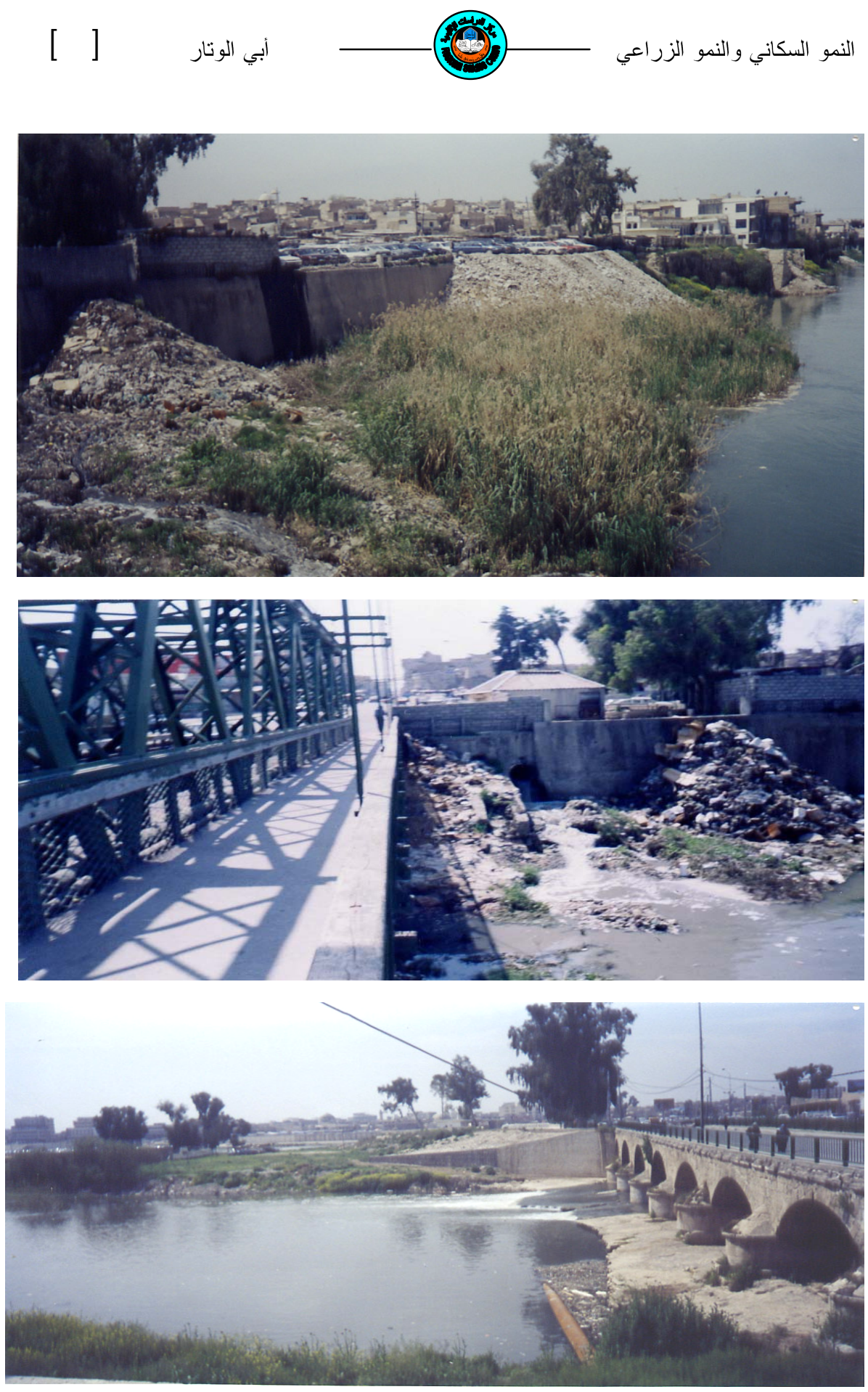
This document was created using 


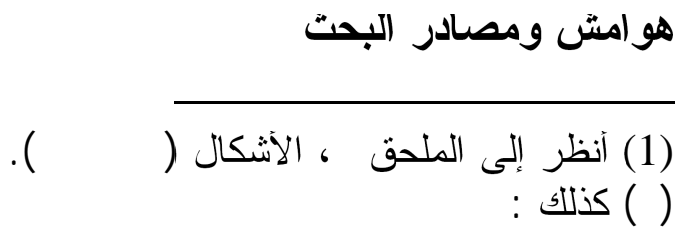

McLachlan, K. "Iraq: Problems of Regional Development", in: Kelidar, A. (ed.), The Integration of Modern Iraq (London: Croom Helm, 1979), PP. 137-138.

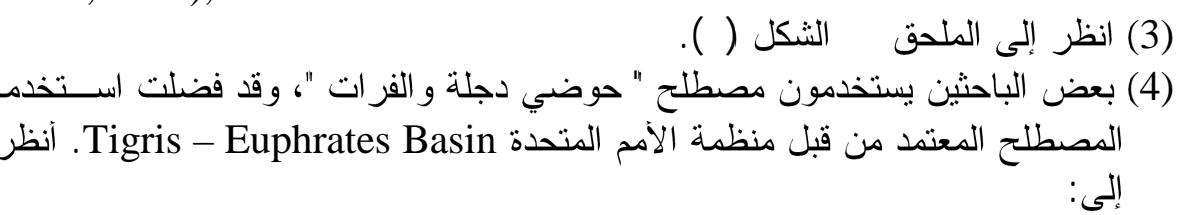

(5)For details:

UNDP, Human Development Report 2006, P. 206.

- UN, Department of Economic and Social Affairs, World Urbanization Prospects: The 2005 Revision (UN Publications: 2006), Tables A.1 and A.2.

- Rabil, R. G., "Operation Termination of Traitors' : The Iraqi Regime Throughout Its Documents", Middle East Review of International Affairs, Vol. 6, No. 3, September 2002 (file://A:I TERMINATION OF TRAITORS.htm).

(6) Penrose, E. \& E. F. Penrose, Iraq: International Relations And

National Development (London: Ernest Benn, 1978), P. 445.

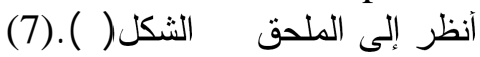

(8) Longrigg, S. H. Oil In The Middle East: Its Discovery And Development, 3ed. Ed. (London: Oxford University Press, 1968), P. 271-272.

(9) Penrose, Ibid., PP. 441-446.

(10) Botas Petroleum Corporation, Annual Report 1998 (http://www.botas.gov.tr/eng/ reports/98.asp\#bas).

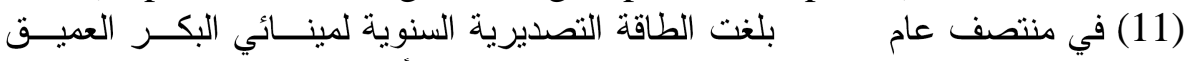

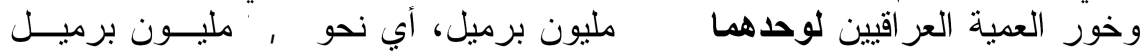

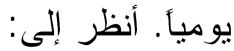

Republic Of Iraq, Ministry Of Information, The Economy Of

Iraq: Development And Perspectives 1958-1976-1980 (Madrid: Fareso, Paseo de la Direction 5, 1977), PP.109-111.

(12) Botas, Ibid.

(13) Chiras, D. D. Environmental Science: Action for Sustainable Future, $2^{\text {nd }}$ ed., (California: Benjamin/Cummings, 1991), P. 115. (14) بسبب زيادة نسبة مشاركة المر آة في القوى العاملة. آنظر إلى: 
UNDP, Human Development Report 1998, PP. 164-165.

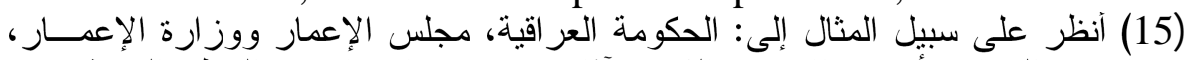

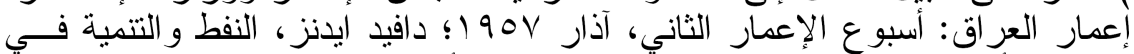

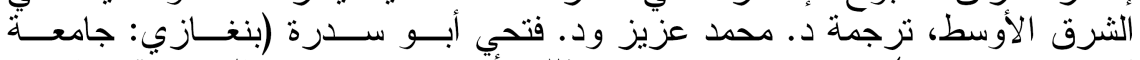

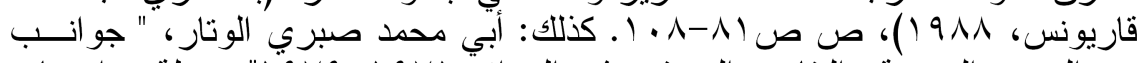

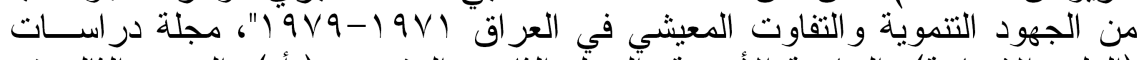

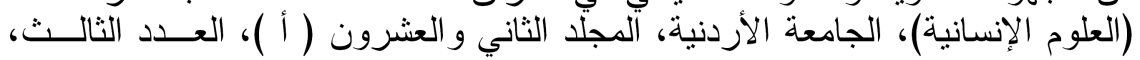
: 1990

Penrose, Ibid, ch. 7 \& 18; Singer, M. The Economic Advance of Turkey 1938-1960 (Ankara: Turkish Economic Society Publications, 1977), Ch. 3 and 4; Davidson, R. M. Turkey: A Short History, $2^{\text {nd }}$ ed. (New Jersey: Eothen Press, 1988), PP. 1-8, 164-165, 180-185; Ohlsson, L. (ed.), Hydropolitics: Conflicts Over Water As A Development Constraint (London: Zed Books, 1998), especially, PP. 91-107.

(16) Pomfert, R. Diverse Paths of Economic Development (London: Harvester/ Wheatsheaf, 1992), PP. 43-45.

(17) Ohlsson, Ibid., PP. 96-120; Richter, et. al., (eds.), Strategies for Intersectoral Water Management in Developing CountriesChallenges and Consequences for Agriculture, Proceedings of the International Workshop Held from $6^{\text {th }}-10^{\text {th }}$ May 1996 in Berlin, Germany (Berlin: German Foundation for International Development, 1997), PP. 178-181; Postal, S. K., Last Oasis: Facing Water Scarcity, Worldwatch Environmental Alert Series (London: Norton \& Company, 1997), PP. 80-83.

كذلك: ملحق ا، الثكلين (س، ع).

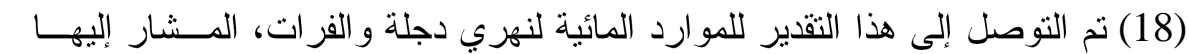

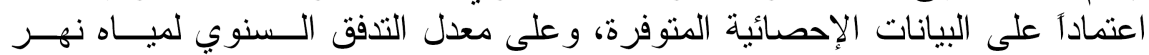

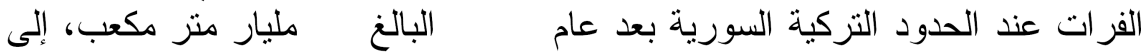

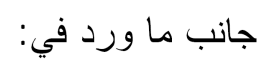

Ohlsson, Ibid., PP. 117-118; Kundell, Ibid., Table 1.

(19) Richter, et. al., Ibid., PP. 181-182.

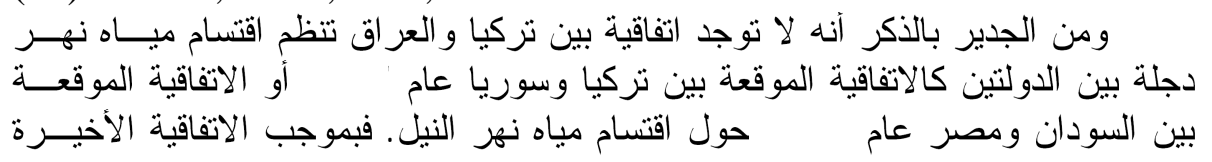




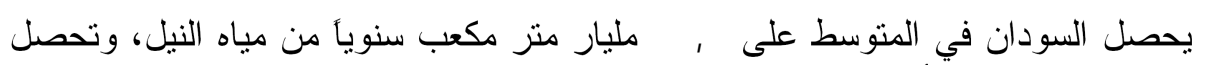

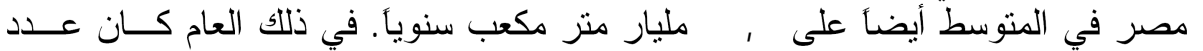

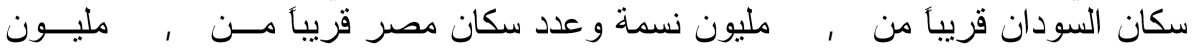

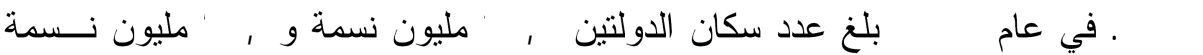

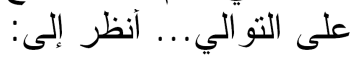

Richter, et. al., Ibid, PP. 171-172; Postal, Ibid., P. 78; and, UNDP, Human Development Report 2006, P. 299.

(20) Richter, et.al. , Ibid, P. 182. 